
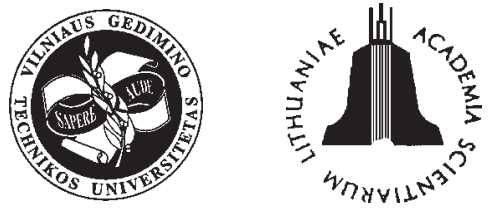

\title{
ACTIONS IMPOSED ON STRUCTURES DURING MAN-MADE ACCIDENTS: PREDICTION VIA SIMULATION-BASED UNCERTAINTY PROPAGATION
}

\author{
Egidijus R. Vaidogas \\ Dept of Reinforced Concrete Structures, Vilnius Gediminas Technical University, Sauletekio al. 11, \\ LT-10223Vilnius, Lithuania.E-mail: erv@st.vtu.lt
}

Received 02 May 2005; accepted 19 July 2005

\begin{abstract}
Prediction of mechanical, thermal, and chemical actions induced during man-made accidents (accidental actions) is of crucial importance to assessing potential damage to structures exposed to these actions. A logical result of such a prediction may be expressed in the form of probabilistic models describing likelihood of occurrence and characteristics of accidental actions. For many types of accidental actions the models are to be selected under the conditions of incomplete knowledge about and/or scarce statistical information on intensities and likelihood of imposition of the actions. This paper proposes a simulation-based procedure intended for a selection of the probabilistic models under these conditions. The proposed procedure is formulated in the context of the classical Bayesian approach to risk assessment. The main idea of it is that statistical samples necessary for fitting the probabilistic action models can be acquired from a stochastic simulation of accident sequences leading to an imposition of accidental actions. Formally, the stochastic simulation of accidents serves the purpose of propagating uncertainties related to the physical phenomena capable of inducing accidental actions. These uncertainties are quantified in line with the classical Bayesian approach. The simulation-based procedure can be used for damage assessment and risk studies within the methodological framework provided by the above-mentioned approach.
\end{abstract}

Keywords: accident, accidental action, risk assessment, uncertainty, Bayesian approach, stochastic simulation.

\section{Introduction}

It has long been known that man-made accidents occurring in industrial and transportation facilities include such adverse, high-energy physical phenomena as explosions, vehicular impacts on structures, internal and external fires (eg, [1, 2]). Mechanical, thermal, and sometimes chemical actions (effects) induced by these phenomena can cause damage to property and threaten people's lives. The most probable targets of these actions are structures and large objects of mechanical engineering which can be viewed as structures. In terms of structural engineering, an action induced during a manmade accident is called an accidental action (AA). Classifications of AAs are given, for instance, in the structural standards ISO 2394 [3] and DNV-OS-A101 [4].

A complete prevention of accidents capable of inducing AAs is not always possible or economically feasible. What is possible it is a limitation of potential damage which can be caused by AAs. Predicting characteristics of AAs is indispensable for assessing this damage. Characteristics of a particular AA can be predicted either by experiment (direct measuring) or by means of mathematical modelling, depending on the knowledge about physical phenomena causing the AA. Full-scale and scaled experiments imitating accidents and allowing direct measuring action characteristics can be expensive and cover only a part of values of the random factors which determine these characteristics (eg, [5, 6]). Characteristics of an AA can also be predicted by a simple calculation or a computer-aided computation in situations where knowledge behind the AA is available in the form of more or less accurate mathematical models. They must be amenable to adapting to a particular accident situation and backed by some data relevant to this situation (eg, [7]). An approach of considerable promise for such a computation is a stochastic (Monte Carlo) simulation of accidents inducing AAs. Examples of predicting AAs by means of the stochastic simulation are presented by Cooke [8] and Hauptmanns [9].

Formally, the stochastic simulation serves the purpose of propagating uncertainties through mathematical models of AAs. The need to deal with the uncertainties stems eventually from the fact that most AAs are rare and unique events of short duration. Predicting AAs will usually face the problem of scarcity of data on their occurrences and necessity of quantifying uncertainties related to action characteristics. The methodology of a quantitative risk assessment (QRA) is naturally suited to solve (alleviate) this problem. QRA provides means of 
dealing with data scarcity and quantifying uncertainties related to physical processes occurring during man-made accidents $[10,11]$. It is also recognised that the design of structures for AAs should be based on principles of QRA [12]. Assessing damage from AAs can be formulated as a QRA problem [13-15].

The present paper follows the idea that principles and methodological approaches developed in QRA can be applied to mathematical predicting AAs by selecting probabilistic models (action models). These models can then be used to assessing damage from AAs. The action model suggested in this paper can be viewed as a generalisation of the model known as "hazard curve". Hazard curves are widely used in QRA [16, 17]. It is discussed how to select the action model on the basis of a general approach to QRA known as a classical Bayesian approach (CBA) [18]. A procedure based on a stochastic simulation of accident sequences (accident simulation) is proposed for the selection of the action model in CBA framework. This procedure relates uncertainties in characteristics of an AA, to uncertainties in physical phenomena, the sequences of which lead to an imposition of the AA, that is, it serves as a tool for uncertainty propagation.

\section{Problem: how to predict accidental actions by se- lecting their models?}

Potential damage to structures and non-structural property from a particular AA can be assessed by means of a probabilistic action model describing this AA. When selected, the action model will serve as a tool for predicting characteristics of the AA and estimating probabilities (frequencies) of damage events in question. The problem considered in this paper is how to select an action model which can be schematically defined as

$$
H(m)=F(O A A) \times P(m \mid O A A),
$$

where $H(m)$ is the frequency (annual probability, probability per year of operation, etc) of exceeding the magnitude $m$ of an AA; $F(O A A)$ is the frequency of occurrence of AA which is considered to be random event $O A A$; and $P(m \mid O A A)$ is the conditional probability of exceeding $m$ given $O A A$.

The action model $H(m)$ breaks down the modelling problem into smaller problems of modelling the likelihood of the random event $O A A$ and modelling action characteristics. Such a partitioning is sometimes used for modelling actions which can be classified as accidental ones, for instance, in forecasting severe local wind phenomena [19].

A more precise definition of the action model $H(m)$ and thus peculiarities of its selection depend on an interpretation of the frequency $F(O A A)$ and probability $P(m \mid O A A)$. Estimating the frequency $F(O A A)$ and fitting the function $P(m \mid O A A)$ solely on the basis of the data gained from occurrences of an AA will be more often than not impossible. Data on AAs are usually sparse or unsuitable to a particular situation of exposure of structures (non-structural property) to AAs, or, what is not uncommon, unavailable at all.

This situation may be alleviated by mixing hard data (relevant experience data) with subjective information (expert opinions, judgements of analysts and analyst groups, etc) as is done in QRA [20]. In view of the selection of the action model $H(m)$, the above-introduced CBA may be defined as a tool for estimating the frequency $F(O A A)$ and probability $P(m \mid O A A)$. CBA uses the concept of probability as the "analyst's measure of uncertainty" or "degree of belief" [18].

\section{Classical Bayesian approach to selecting models for accidental actions}

\subsection{Form of action model}

In the setting of CBA, the frequency $F(O A A)$ and probability $P(m \mid O A A)$ are treated as true, even if unobservable and unknown, quantities. Both $F(O A A)$ and $P(m \mid O A A)$ express the aleatory (stochastic) uncertainty in the random events $O A A$ and "exceedance of $m$ given $O A A$ ". Another type of uncertainty distinguished in CBA is the epistemic (state-of-knowledge) uncertainty in the true values of $F(O A A)$ and $P(m \mid O A A)$. Thus an action model based on CBA should incorporate both types of uncertainty.

In line with CBA, the action model $H(m)$ can be defined as

$$
\begin{aligned}
H_{X}(\boldsymbol{x}):= & \left\{F_{P_{a}}\left(p_{a} \mid \pi_{\alpha}\right),\left(\left(1-F_{X_{i}}\left(\boldsymbol{x} \mid \pi_{x_{i}}\right)\right), p_{i}\right),\right. \\
& (i=1,2, \ldots, n)\}
\end{aligned}
$$

where $\boldsymbol{x}$ is the vector of action characteristics; $\boldsymbol{X}$ is the random vector which models an aleatory uncertainty in $\boldsymbol{x} ; p_{a}$ is the frequency of $O A A ; P_{a}$ is the random variable (rv) which expresses an epistemic uncertainty in $p_{a}$; $F_{P_{a}}\left(p_{a} \mid \pi_{\alpha}\right)$ is the cumulative distribution function (cdf) of $P_{a}$ with a parameter vector $\pi_{a} ; F_{X_{i}}\left(\boldsymbol{x} \mid \pi_{x_{i}}\right)$ $(i=1,2, \ldots, n)$ are the cdfs of the vector $\boldsymbol{X}$ with the same argument vector $\boldsymbol{x}$ and individual parameter vectors $\pi_{x_{i}} ; p_{i}$ are the probabilities expressing epistemic uncertainties in cdfs $F_{X_{i}}\left(\boldsymbol{x} \mid \pi_{x_{i}}\right)$. A simplified example of such an action model is the family of hazard curves of ground motion acceleration used in a seismic risk assessment [17].

The definition (1) follows principles of CBA which require to keep apart the aleatory and epistemic uncertainties in the final form of a risk analysis, say, a probability of the top event of a fault tree [18]. In the community of risk analysts, it is argued that distinguishing between different types of uncertainty does not have a solid basis and is done only for convenience of modelling and analysing complex systems [10,21].

It follows from the definition (1) that a selection of the action model $H_{X}(\boldsymbol{x})$ amounts to a selection of cdf $F_{P_{a}}\left(p_{a} \mid \pi_{\alpha}\right)$ and the family of cdfs $F_{X_{i}}\left(\boldsymbol{x} \mid \pi_{x_{i}}\right)$ 


\begin{tabular}{|c|c|c|c|}
\hline $\begin{array}{c}\text { Accidental release of } \\
\text { LPG (initiating event) }\end{array}$ & $\begin{array}{c}\text { Amount of released LPG is } \\
\text { sufficient to generate an } \\
\text { explosion }\end{array}$ & Ignition of vapour cloud & Detonation of vapour cloud (OAA) \\
\hline \multicolumn{1}{|c|}{\begin{tabular}{|l|l|} 
Models describing \\
loss of containment \\
of a LPG vessel
\end{tabular}} \\
\hline
\end{tabular}

Fig 1. Event tree diagram with a path leading to an unconfined vapour cloud explosion (UVCE); mathematical models describing physical phenomena leading to UVCE are listed in rectangles (LPG - liquefied petroleum gas)

$(i=1,2, \ldots, n)$ as well as assignment of the respective weights $p_{i}$. This selection is considered in the remainder of Sec 3 as well as Secs 4 and 5 while Sec 6 discusses an application of $H_{X}(\boldsymbol{x})$ to damage assessment.

\subsection{Selection of action model}

\subsubsection{Dealing with scarcity of data}

In most cases the analyst will face a complete lack of data allowing a direct fitting the cdfs $F_{P_{a}}\left(p_{a} \mid \pi_{\alpha}\right)$ and $F_{X_{i}}\left(\boldsymbol{x} \mid \pi_{x_{i}}\right)$. In principle, some data are almost always available, say, from back (post-mortem) investigations of a small number of analogous accidents. However, it is usually impossible to group the data in samples which are large enough for fitting cdfs $F_{P_{a}}\left(p_{a} \mid \pi_{\alpha}\right)$ and $F_{X_{i}}\left(\boldsymbol{x} \mid \pi_{x_{i}}\right)$.

The situation of the virtual lack of data is commonly encountered when the analyst has to do with unique industrial equipment and/or unique exposure to AA. This situation cannot be considered hopeless if the analyst can employ probabilistic and deterministic models describing physical phenomena the sequences of which lead to $O A A$. The selection of cdfs $F_{P_{a}}\left(p_{a} \mid \pi_{\alpha}\right)$ and $F_{X_{i}}\left(\boldsymbol{x} \mid \pi_{x_{i}}\right)$ can be based on these models.

For example, the event tree diagram shown in Fig 1 lists existing models which can be used to select cdfs $F_{P_{a}}\left(p_{a} \mid \pi_{\alpha}\right)$ and $F_{X_{i}}\left(\boldsymbol{x} \mid \pi_{x_{i}}\right)$ for an unconfined vapour cloud explosion (UVCE) (see the book [2] and references cited therein). The models given in Fig 1 are aligned along a path of event tree diagram. This suggests the use of the models for deciding, which of the alternatives represented by event tree branching points may take place in a numerical simulation of the UVCE accident.

The mathematical models describing physical phenomena leading to $O A A$ are normally developed independently of each other. Therefore it is hardly probable that the entire set of models covering all phenomena, which can escalate into $O A A$, will be present in a readyto-use form. In the author's experience, extra effort will usually be required to make the models "compatible" with each other. This statement is true for the models mentioned in Fig 1.
The central idea of this paper is that in some cases cdfs $F_{P_{a}}\left(p_{a} \mid \pi_{\alpha}\right)$ and $F_{X_{i}}\left(\boldsymbol{x} \mid \pi_{x_{i}}\right)$ can be selected using a stochastic simulation of accident courses (scenarios) involving $O A A$. This accident simulation can generate samples of action characteristics and frequencies of $O A A$. The cdfs $F_{X_{i}}\left(\boldsymbol{x} \mid \pi_{x_{i}}\right)$ and $F_{P_{a}}\left(p_{a} \mid \pi_{\alpha}\right)$ can be fitted to the generated samples. The accident simulation can be used for an uncertainty propagation and relate probabilistic models of the physical phenomena preceding $O A A$ to cdfs $F_{P_{a}}\left(p_{a} \mid \pi_{\alpha}\right)$ and $F_{X_{i}}\left(\boldsymbol{x} \mid \pi_{x_{i}}\right)$. Such propagation should supplement a usual propagation of uncertainties through logical models of man-made accidents (event trees, fault trees).

\subsubsection{Procedure of accident simulation}

The uncertainty propagation via the accident simulation is visualised by Fig 2 . The accident is represented by an event tree path $E_{0}, E_{1}, \ldots, E_{n_{k}-1}$ in which $E_{0}$ is an initiating event, $E_{n_{k}-1}$ is the event $O A A$, and $n_{k}-1$ is the number of branching points. A "loop-in-loop" simulation procedure can be applied to the propagation $[22,23]$. An application of the two loops stems from the necessity to distinguish between the aleatory and epistemic uncertainties expressed by the model sets

$$
\Xi_{1}:=\left\{F_{P_{0}}\left(p_{0} \mid \pi_{P_{0}}\right), F_{0}\left(z_{0} \mid \pi_{0}\right), F_{\Pi_{0}}\left(\pi_{0} \mid \pi_{\Pi_{0}}\right)\right\}
$$

and

$$
\Xi_{2}:=\left\{\boldsymbol{m}_{k}\left(z_{k} \mid \pi_{k}\right), F_{\Pi_{k}}\left(\pi_{k} \mid \pi_{\Pi_{k}}\right)\left(k=1,2, \ldots, n_{k}\right)\right\} .
$$

Elements of the model set $\boldsymbol{\Xi}_{1}$ describe the initiating event $E_{0}$ (Fig 2): $F_{P_{0}}\left(p_{0} \mid \pi_{P_{0}}\right)$ is the cdf of the rv $P_{0}$ which is used to model the epistemic uncertainty in the frequency (annual probability, probability per year of operation, etc) $p_{0}$ of $E_{0} ; F_{0}\left(z_{0} \mid \pi_{0}\right)$ is the cdf of the random vector $Z_{0}$ used to model the aleatory uncertainty in characteristics of $E_{0} ; F_{\Pi_{0}}\left(\pi_{0} \mid \pi_{\Pi_{0}}\right)$ is the cdf of the random vector $\Pi_{0}$ which is used to model the epistemic uncertainty in vector $\pi_{0} ; \pi_{P_{0}}, \pi_{0}$, and $\pi_{\Pi_{0}}$ are the parameter vectors of cdfs $F_{P_{0}}(\cdot), F_{0}(\cdot)$, and $F_{\Pi_{0}}(\cdot)$, respectively.

The model set $\boldsymbol{\Xi}_{2}$ describes the events succeeding the initiating event, $E_{k}\left(k=1,2, \ldots, n_{k}-1\right)$ (Fig 2). 


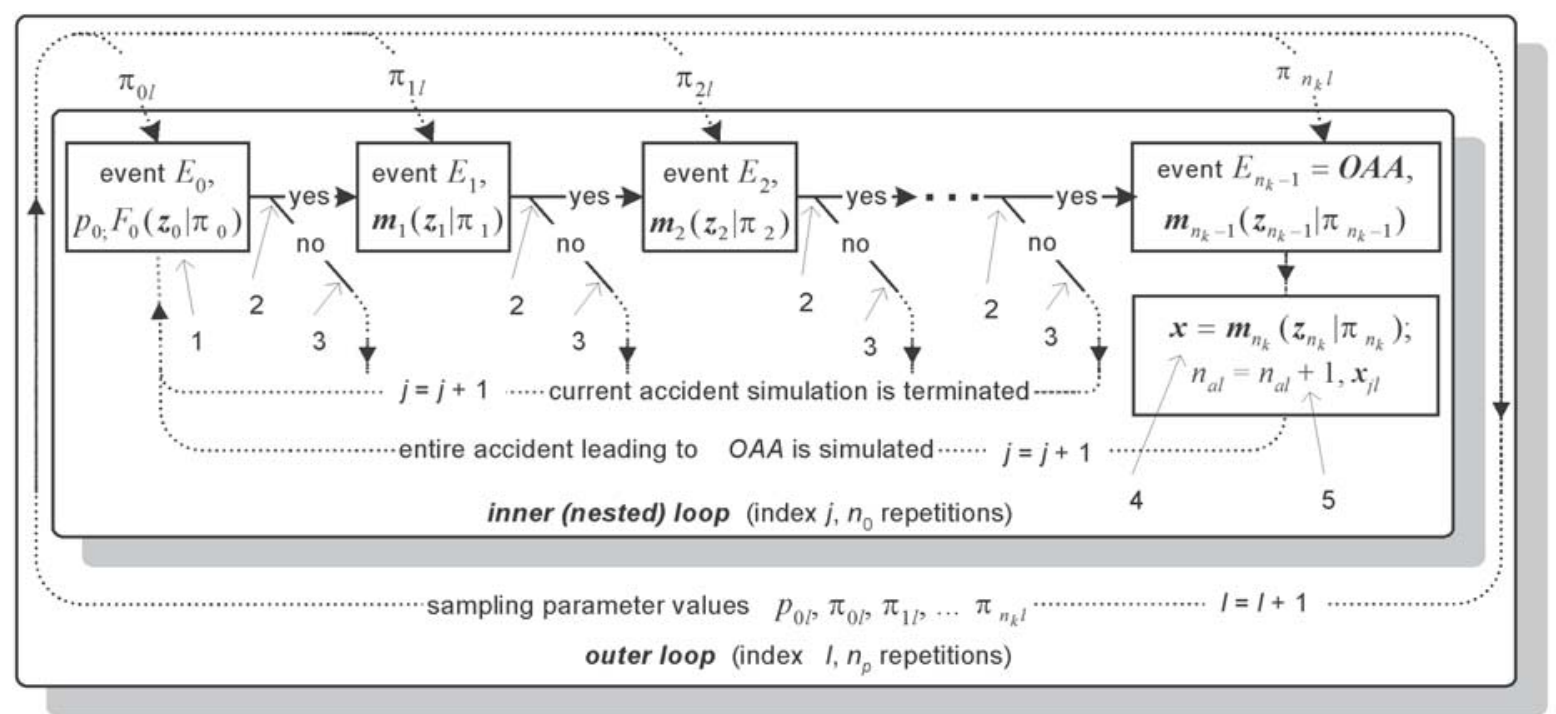

Fig 2. "Loop-in-loop" procedure used for an accident simulation: 1 - initiating event, 2 - branching points of an event tree path, 3 - termination of the $j$ th simulation when $O A A$ does not take place, 4 - mathematical model yielding action characteristics, 5 - results of the $j$ th simulation in case of $O A A$

The model $\boldsymbol{m}_{k}\left(\boldsymbol{z}_{k} \mid \boldsymbol{\pi}_{k}\right)$ describes the physical phenomenon represented by the event $E_{k}$, where $z_{k}$ is the input vector expressing known information; $\pi_{k}$ is the vector of those model parameters which are considered uncertain in an epistemic sense. The model $\boldsymbol{m}_{k}\left(\boldsymbol{z}_{k} \mid \pi_{k}\right)$ is a vector-function defined as

$$
\boldsymbol{m}_{k}\left(z_{k} \mid \pi_{k}\right)=\left(\begin{array}{l}
m_{1 k}\left(z_{k} \mid \pi_{k}, \pi, \pi^{\prime}, \pi^{\prime \prime}, \ldots\right) \\
m_{2 k}\left(z_{k} \mid \pi_{k}, \pi, \pi^{\prime}, \pi^{\prime \prime}, \ldots\right) \\
\vdots
\end{array}\right),
$$

where $\pi, \pi^{\prime}, \pi^{\prime \prime}, \pi^{\prime \prime \prime}, \ldots$ are those model parameters which can be considered either certain or uncertain in an aleatory sense. A mathematical structure of the components $m_{1 k}(\cdot), m_{2 k}(\cdot), \ldots$ is purely deterministic if $\pi, \pi^{\prime}, \pi^{\prime \prime}, \pi^{\prime \prime \prime}, \ldots$ are considered certain or, alternatively, contains probabilistic models which express aleatory uncertainties in $\pi, \pi^{\prime}, \pi^{\prime \prime}, \pi^{\prime \prime \prime}, \ldots$. In the latter case the output variables $m_{1 k}(\cdot), m_{2 k}(\cdot), \ldots$ will be uncertain in the aleatory sense.

The cdfs $F_{P_{0}}\left(p_{0} \mid \pi_{P_{0}}\right)$ and $F_{\Pi_{k}}\left(\pi_{k} \mid \pi_{\Pi_{k}}\right) \quad(k=0$, $\left.1,2, \ldots, n_{k}\right)$ in the sets $\boldsymbol{\Xi}_{1}$ and $\boldsymbol{\Xi}_{2}$ can represent prior or posterior probability distributions (pds) depending on the availability of hard data. Assigning and updating these pds are discussed in Sec 5. The role of the models $\boldsymbol{m}_{k}\left(z_{k} \mid \pi_{k}\right)$ in the accident simulation is twofold:

(a) models $\boldsymbol{m}_{k}\left(z_{k} \mid \pi_{k}\right)$ are used for the accident simulation; output components of each model $\boldsymbol{m}_{k}\left(z_{k} \mid \pi_{k}\right)$ $\left(k<n_{k}\right)$ serve as input values of the subsequent models $\boldsymbol{m}_{k}\left(z_{k+1} \mid \pi_{k+1}\right), \ldots, \boldsymbol{m}_{n_{k}}\left(z_{n_{k}} \mid \pi_{n_{k}}\right)$; the model applied at the end, $\boldsymbol{m}_{n_{k}}\left(z_{n_{k}} \mid \pi_{n_{k}}\right)$, yields action characteristics, see Fig 2; some models can be time histories of physical phenomena and this can be denoted by adding a time variable t to model arguments, namely, $\boldsymbol{m}_{k}\left(\boldsymbol{z}_{k}, t \mid \pi_{k}\right)$; (b) each of the models $\boldsymbol{m}_{k}\left(z_{k} \mid \pi_{k}\right)\left(k<n_{k}\right)$ is also used to decide which of the alternative accident courses represented by the kth event tree branching takes place in the jth repetition of the inner loop, see Fig 2.

The rule used to decide at the kth branching represented by the complementary events $E_{k}$ and $\bar{E}_{k}$ can be expressed as

$$
\mathbf{1}\left(z_{k j} \mid \pi_{k l}\right)= \begin{cases}1 & \text { if } \boldsymbol{m}_{k}\left(z_{k j} \mid \pi_{k l}\right) \in \Delta_{k}\left(\text { event } E_{k} \text { occurs }\right) \\ 0 & \text { if } \boldsymbol{m}_{k}\left(z_{k j} \mid \pi_{k l}\right) \notin \Delta_{k}\left(\text { event } \bar{E}_{k} \text { occurs }\right)\end{cases}
$$

where $\Delta_{k}$ is the output domain defining an occurrence of $E_{k}$ if the vector $\boldsymbol{m}_{k}\left(z_{k j} \mid \pi_{k l}\right)$ computed in the $j$ th repetition of the inner loop and the $l$ th repetition of the outer loop belongs to $\Delta_{k}$ componentwise and a non-occurrence otherwise.

The $j$ th repetition of the inner loop is terminated and a new one started as soon as the current binary function $\mathbf{1}\left(z_{k j} \mid \boldsymbol{\pi}_{k l}\right)$ takes zero value (Fig 2). The result $\prod_{k=1}^{n_{k}-1} \mathbf{1}\left(z_{k j} \mid \pi_{k l}\right)$ means that $O A A$ takes place in the $j$ th repetition of the inner loop and $l$ th repetition of the outer loop. The $n_{0}$ repetitions of the inner loop yield a simulated sample of action characteristics, $\boldsymbol{x}_{1 l}, \boldsymbol{x}_{2 l}, \ldots$, $\boldsymbol{x}_{n_{a l} l}$, and a relative frequency of $O A A$ given by the ratio $n_{a l} / n_{0}$. The subscript $l$ in the above notations means that the sample and the relative frequency are related to the lth repetition of the outer loop.

The outer loop is used for sampling the parameter values $p_{01}$ and $\pi_{k l}$ from pds represented by cdfs $F_{P_{0}}\left(p_{0} \mid \pi_{P_{0}}\right)$ and $F_{\Pi_{k}}\left(\pi_{k} \mid \pi_{\Pi_{k}}\right)\left(k=0,1,2, \ldots, n_{k}\right)$. On sampling the parameter values $p_{01}$ and $\pi_{k l}(k=0,1$, $\left.2, \ldots, n_{k}\right)$, they serve as input values of the inner loop, and this is repeated $n_{0}$ times in each repetition of the outer loop. The latter is repeated $n_{p}$ times. 


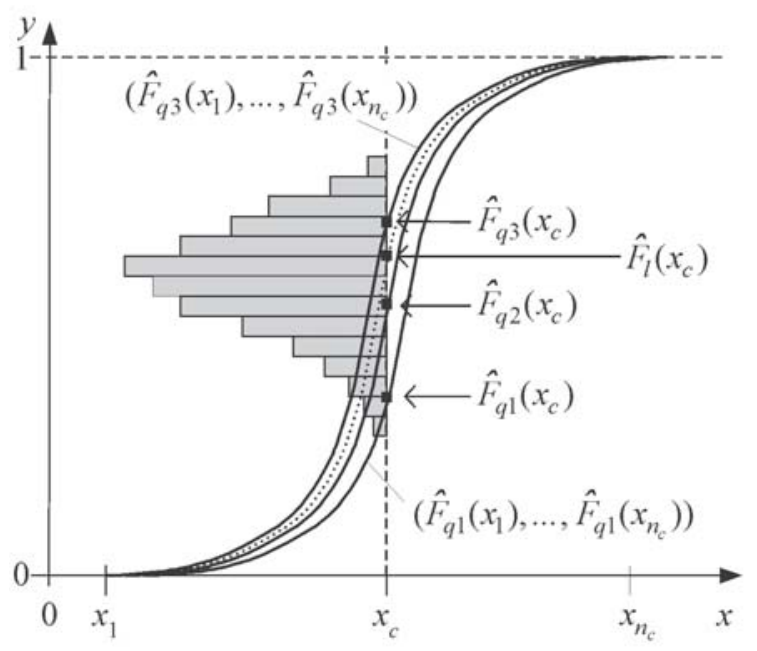

Fig 3. One-dimensional visualisation of the heuristic procedure for selecting the family of distribution functions $F_{X_{i}}\left(\boldsymbol{x} \mid \pi_{x_{i}}\right)(i=1,2, \ldots, n)$ in the case $n=4$

Consequently, an application of the "loop-in-loop" procedure requires simulating the accident $n_{p} \times n_{0}$ times and yields a sample of estimates of the frequency $P_{a}$, namely,

$$
f r_{l}=p_{0 l} \frac{n_{a l}}{n_{0}}\left(l=1,2, \ldots, n_{p}\right)
$$

and $n_{p}$ samples of action characteristics $\mathbf{x}_{l}(l=1,2, \ldots$, $\left.n_{p}\right)$, each defined as

$$
\mathbf{x}_{l}=\left(\boldsymbol{x}_{j l}, j=1,2, \ldots, n_{a l}\right) .
$$

These samples can serve as initial statistical material for fitting cdfs $F_{P_{a}}\left(p_{a} \mid \pi_{\alpha}\right)$ and $F_{X_{i}}\left(\boldsymbol{x} \mid \pi_{x_{i}}\right)$ as well as assigning the weights $p_{i}(i=1,2, \ldots, n)$.

\subsubsection{Fitting probability distributions}

Fitting cdf $F_{P_{a}}\left(p_{a} \mid \pi_{\alpha}\right)$ to the sample $f r_{l}(l=1,2$, $\left.\ldots, n_{p}\right)$ is a trivial statistical problem. It can be solved by standard procedures of a univariate statistical analysis.

In contrast to cdf $F_{P_{a}}\left(p_{a} \mid \pi_{\alpha}\right)$, the selection of the family of cdfs $F_{X_{i}}\left(\boldsymbol{x} \mid \pi_{x_{i}}\right)(i=1,2, \ldots, n)$ and assignment of the weights $p_{i}$ to these cdfs is not straightforward. Any formal and ready-to-use statistical recipes to do this seem not to be available. Because of this a heuristic procedure to the choice of the family of the probability distributions is proposed in remainder of this subsection.

The main idea of the proposed procedure consists in a choice of the cdfs $F_{X_{i}}\left(\boldsymbol{x} \mid \pi_{x_{i}}\right)$ by fitting them to respective clusters of samples $\mathbf{x}_{i}^{\prime}(i=1,2, \ldots, n)$, each obtained by grouping the samples $\mathbf{x}_{l}$ and defined as $\mathbf{x}_{i}^{\prime}=$ $\left(\mathbf{x}_{l}, l \in I_{i}\right)$, where $I_{i}$ is the subset of values of the index $l$ denoting numbers of all samples which belong to the ith cluster. Simulated values of the vector $\boldsymbol{X}$ (components of the vectors $\mathbf{x}_{l}$ ) are pooled together in the clusters $\mathbf{x}_{i}^{\prime}(i=1,2, \ldots, n)$ in such a way that each of the samples $\mathbf{x}_{l}$ belongs only to one cluster, that is, $I_{i} \cap I_{k}=\varnothing \quad(i \neq k$ and $i, k=1,2, \ldots, n)$. The sample $\mathbf{x}_{l}$ is associated with the cluster, the number which, $i$, is equal to

$$
i=\underset{1 \leq j \leq n}{\operatorname{argmin}}\left(\sum_{c=1}^{n_{c}}\left|\hat{F}_{l}\left(x_{c}\right)-0.5\left(\hat{F}_{q j}\left(x_{c}\right)-\hat{F}_{q, j-1}\left(x_{c}\right)\right)\right|\right),
$$

with $\hat{F}_{q 0}\left(x_{c}\right)=0$ and $\hat{F}_{q n}\left(x_{c}\right)=1$, where $x_{c}(c=1,2$, $\left.\ldots, n_{c}\right)$ is a set of points dividing ranges of components of the vector $\boldsymbol{X}$ into disjoint class intervals; $\hat{F}_{l}\left(x_{c}\right)$ is the cumulative frequency at the point $x_{c}$ (value of empirical distribution function at $x_{c}$ ) computed for the sample $\mathbf{x}_{l}$ (Fig 3$) ; \hat{F}_{q j}\left(x_{c}\right)$ and $\hat{F}_{q, j-1}\left(x_{c}\right)$ is the pair of values of cumulative relative frequency at the point $x_{c}$ defining the jth cluster for this point.

Pooling the samples $\mathbf{x}_{l}\left(l=1,2, \ldots, n_{p}\right)$ is based on the sets of cumulative relative frequencies

$$
\begin{aligned}
& \hat{F}_{q 1}\left(x_{1}\right), \hat{F}_{q 1}\left(x_{2}\right), \ldots, \ldots, \hat{F}_{q 1}\left(x_{c}\right), \ldots \hat{F}_{q 1}\left(x_{n_{c}}\right) ; \\
& \hat{F}_{q 2}\left(x_{1}\right), \hat{F}_{q 2}\left(x_{2}\right), \ldots, \hat{F}_{q 2}\left(x_{c}\right), \ldots \hat{F}_{q 2}\left(x_{n_{c}}\right) ; \\
& \vdots \\
& \hat{F}_{q, n-1}\left(x_{1}\right), \hat{F}_{q, n-1}\left(x_{2}\right), \ldots, \hat{F}_{q, n-1}\left(x_{c}\right), \ldots \hat{F}_{q, n-1}\left(x_{n_{c}}\right) .
\end{aligned}
$$

Each set is used to separate two adjacent clusters. In the above sets, the values $\hat{F}_{q j}\left(x_{c}\right) \quad(j=1,2, \ldots, n-1)$ are empirical quantiles with levels $q_{j}$ computed for the sample $\hat{F}_{l}\left(x_{c}\right) \quad\left(l=1,2, \ldots, n_{p}\right)$ (Fig 3). The probabilistic weights $p_{1}, p_{2}, \ldots, p_{n}$ and levels $q_{1}, q_{2}, \ldots, q_{n-1}$ are preset in such a way that $\sum_{i=1}^{n} p_{i}=1, q_{1}<q_{2}<\ldots<$ $q_{n-1}$, and $q_{j}=\sum_{i=1}^{j} p_{i}(j=1,2, \ldots, n-1)$.

The probabilities pi can be specified relatively free according to how we want to group the samples $\mathbf{x}_{l}$. Thus the distribution of epistemic uncertainty in probabilistic models of the vector $\boldsymbol{X}$, that is, the set of probabilities $p_{1}, p_{2}, \ldots, p_{n}$ is specified in the proposed procedure in advance.

\section{Illustrative case study}

The simulation-based procedure suggested in Sec 3 for selecting the action model $H_{X}(\boldsymbol{x})$ can now be illustrated by a case study. The consideration of Sec 3 started with an example of accident involving AA generated by vapour cloud explosion (UVCE, Fig 1). A stochastic simulation of such an accident is complicated and complex. Moreover, a description of this simulation in sufficient detail is too cumbersome to be presented in this paper. Therefore the case study given below will analyse a less complicated accident which, nevertheless, can also result in inducing explosive actions. 


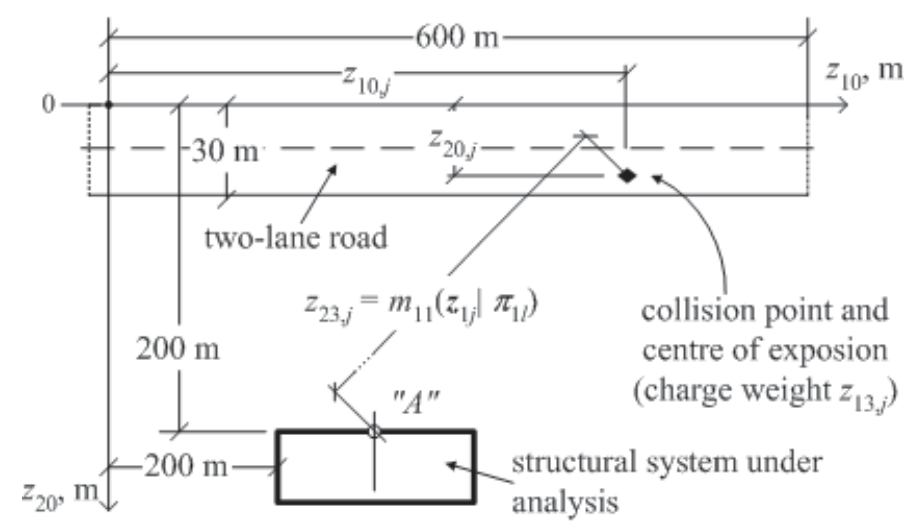

Fig 4. Situation of an accident (explosion) on road in the $j$ th inner loop and $l$ th outer loop repetition

\subsection{Problem: selection of model for an explosive ac- tion generated by a vehicular collision}

The action model $H_{X}(\boldsymbol{x})$ defined by Eq (1) is to be selected to describe peak positive overpressure $x_{1}$ and positive impulse $x_{2}$ of an incident blast wave which can be generated by an accidental explosion. The explosion can occur on a two lane road $(600 \mathrm{~m} \times 30 \mathrm{~m}$ road section) and can be triggered off by a collision of vehicle carrying explosive materials (vehicle A) with an opposite vehicle (vehicle B) (Fig 4). The incident overpressure and incident impulse are to be estimated for the point " $A$ " on the facade of the hypothetical structural system built in the vicinity of the road section.

A logical model (event tree) of the accident is shown in Fig 5. The collision is described by the probabilistic model $H_{0}\left(\mathrm{z}_{0} \mid \pi_{0}, p_{0}\right)$. The event tree contains two branching points (alternatives in accident courses), and the models $\boldsymbol{m}_{1}\left(\boldsymbol{z}_{1} \mid \pi_{1}\right)$ and $m_{2}\left(z_{2} \mid \pi_{2}\right)$ are used to choose between the alternatives during the accident simulation. The model $\boldsymbol{m}_{3}\left(z_{3} \mid \pi_{3}\right)$ is used to relate the overpressure $x_{1}$ and impulse $x_{2}$ to physical values determining these two characteristics of the incident blast wave. A detailed description of all four models is given in the subsequent section 4.2 .

\subsection{Models used to the simulation of the stochastic simulation of the accident}

\subsubsection{Collision of vehicles}

The model $H_{0}\left(z_{0} \mid \pi_{0}, p_{0}\right)$ describes the initiating event $E_{0}$ (collision of vehicles A and B, Fig 5). $H_{0}\left(z_{0} \mid \pi_{0}, p_{0}\right)$ is used to express an aleatory uncertainty related to a likelihood of the initiating event $E_{0}$ (collision) and its characteristics. The model has the structure

$$
H_{0}\left(z_{0} \mid \pi_{0}, p_{0}\right):=\left\{p_{0}, F_{0}\left(z_{0} \mid \pi_{0}\right)\right\},
$$

where $p_{0}$ is the collision frequency (annual probability) $\left(\right.$ year $\left.^{-1}\right) ; F_{0}\left(z_{0} \mid \pi_{0}\right)$ is the cdf defined as the product $\prod_{i=1}^{7} F_{Z_{i 0}}\left(z_{i 0} \mid \pi_{i 0}\right)$, in which $Z i_{0}(i=1,2, \ldots, 7)$ are rvs used to model the aleatory uncertainty in collision characteristics (components of $\left.z_{0}\right) ; F_{Z_{i 0}}\left(z_{i 0} \mid \pi_{i 0}\right)$ are cdfs of $Z_{i 0}$ s with the parameter vectors $\pi_{i 0}$.

The arguments of the model (collision charactertistics $)$ are represented by the vector $z_{0}=\left(z_{10}\right.$, $\left.z_{20}, \ldots, z_{70}\right)^{T}$, where $z_{10}$ and $z_{20}$ is the collision coordinates $(\mathrm{m})$, Fig $4 ; z_{30}$ is the speed of vehicle A at a collision moment $(\mathrm{m} / \mathrm{s}) ; z_{40}$ is the speed of vehicle $\mathrm{B}$ at the collision moment $(\mathrm{m} / \mathrm{s}) ; z_{50}$ is the mass of vehicle B $(\mathrm{kg})$; $z_{60}$ is the dimensionless variable expressing a mechanical behaviour of vehicles $A$ and $B$ at the collision

\begin{tabular}{|c|c|c|c|}
\hline $\begin{array}{c}\text { Initiating event } \\
\text { (collision of vehicles } \mathrm{A} \text { and } \mathrm{B})\end{array}$ & $\begin{array}{c}\text { Energy of collision exceeds tolerable value } \\
\text { incapable to trigger explosion in vehicle } \mathrm{A}\end{array}$ & $\begin{array}{c}\text { Explosion of charge in vehicle } \mathrm{A} \\
(\mathrm{O} A \mathrm{~A})\end{array}$ \\
\hline
\end{tabular}

Fig 5. Event tree diagram with a path leading to an explosion in consequence of a vehicular collision; mathematical models related to events comprising the path are shown in rectangles 
Table 1. Random variables expressing stochastic uncertainty in characteristics of the initiating event $E_{0}$ (vehicular collision)

\begin{tabular}{|c|c|c|}
\hline Variable & Distribution & Vector of distribution parameters \\
\hline$Z_{10}$ & $U(0,600)^{\mathrm{a})}$ & $\begin{array}{l}\pi_{10}=(0 \mathrm{~m}, 600 \mathrm{~m})^{T} \text { (a uniform distribution over the range } 0 \text { to } \\
600 \mathrm{~m})\end{array}$ \\
\hline$Z_{20}$ & $U(0,30)$ & $\pi_{20}=(0 \mathrm{~m}, 30 \mathrm{~m})^{T}$ \\
\hline$Z_{30}$ & $N(13,9 ; 17,4)^{b)}$ & $\begin{array}{l}\pi_{30}=\left(13,9 \mathrm{~m} / \mathrm{s}, 17,4(\mathrm{~m} / \mathrm{s})^{2}\right)^{T}(\text { a normal distribution with the mean of } \\
\left.13,9 \mathrm{~m} / \mathrm{s} \text { and the variance of } 17,4(\mathrm{~m} / \mathrm{s})^{2}\right)\end{array}$ \\
\hline$Z_{40}$ & $N(22,2 ; 30,9)$ & $\pi_{40}=\left(22,2 \mathrm{~m} / \mathrm{s}, 30,9(\mathrm{~m} / \mathrm{s})^{2}\right)^{T}$ \\
\hline$Z_{50}$ & $\left.L(7,8044 ; 0,19804)^{\mathrm{c}}\right)$ & $\begin{array}{l}\pi_{50}=(7,8044,0,19804)^{T} \text { (a lognormal distribution with the mean of } \\
2500 \mathrm{~kg} \text { and the standard deviation of } 500 \mathrm{~kg} \text { ) }\end{array}$ \\
\hline$Z_{60}$ & $B e\left(\pi_{1,60}, \pi_{2,60}\right)^{\mathrm{d})}$ & $\begin{array}{l}\qquad \pi_{60}=\left(\pi_{1,60}, \pi_{2,60}\right)^{T} \text { (a beta distribution with the uncertain mean } \pi_{1,60} \\
\text { and variance } \pi_{2,60} \text { related to its alpha and beta parameters by the respective } \\
\left.\text { expressions } \pi_{1,60}\left(\pi_{1,60}\left(1-\pi_{1,60}\right) / \pi_{2,60}-1\right) \text { and } \pi_{1,60}\left(1-\pi_{1,60}\right)^{2} / \pi_{2,60}+\pi_{1,60}-1\right) \text {; the } \\
\text { epistemic probability distributions of } \pi_{1,60} \text { and } \pi_{2,60} \text { are specified in Table } 2\end{array}$ \\
\hline$Z_{70}$ & Discrete & $\begin{array}{l}\text { the vector of distribution parameters, } \pi_{70} \text {, is not used in the explicit } \\
\text { form; } Z_{70} \text { is a discrete rv distributed over the values } 100 \mathrm{~kg}, 200 \mathrm{~kg} \text { and } \\
500 \mathrm{~kg} \text { with the probability mass function given by the set } \\
\left\{P\left(Z_{70}=100\right)=0,4, P\left(Z_{70}=200\right)=0,3, P\left(Z_{70}=500\right)=0,3\right\}\end{array}$ \\
\hline
\end{tabular}

$\left(0 \leq z_{60} \leq 1\right.$; if $z_{60}=0$, the vehicles are considered perfectly plastic bodies; if $z_{60}=1$, the vehicles are considered perfectly elastic bodies); $z_{70}$ is the mass of the explosive in vehicle A (charge mass) (kg). Probability distributions expressing the stochastic uncertainty in components of $z_{0}$ are specified in Table 1 .

The uncertainty in the collision frequency $p_{0}$ is expressed by a rv. $P_{0}$ having a gamma distribution with cdf $F_{P_{0}}\left(p_{0} \mid \pi_{P_{0}}\right)$ and the parameter vector (alpha and beta) $\pi_{P_{0}}=\left(2,10\right.$ year), that is, $P_{0} \sim G(2,10)$ (the mean, mode and standard deviation of $P_{0}$ are equal to 0,2 year $^{-1}, 0,1$ year $^{-1}$, and 0,1414 year $^{-1}$, respectively). Uncertainty in components of $\pi_{60}$ is expressed by the random vector $\Pi_{60}=\left(\Pi_{1,60}, \Pi_{2,60}\right)^{T}$ with cdf.

$$
F_{\Pi_{60}}\left(\pi_{60} \mid \pi_{\Pi_{60}}\right)=\prod_{i=1}^{2} F_{\Pi_{i, 60}}\left(\pi_{i, 60} \mid \pi_{\Pi_{i, 60}}\right) .
$$

Epistemic probability distributions of the rvs $\Pi_{1,60}$ and $\Pi_{2,60}$ are specified in Table 2 .

Components of $z_{0}$ serve as input variables of the subsequent models $\boldsymbol{m}_{1}\left(z_{1} \mid \pi_{1}\right)$ and $\boldsymbol{m}_{3}\left(z_{3} \mid \pi_{3}\right)$. The rvs $Z_{i 0}(i=1,2, \ldots, 7)$ are assumed to be independent ones only for simplicity sake. The pds of $Z_{i 0}$ s were chosen hypothetically. Assigning and updating the pds represented by cdfs $F_{P_{0}}\left(p_{0} \mid \pi_{P_{0}}\right)$ and $F_{\Pi_{60}}\left(\pi_{60} \mid \pi_{\Pi_{60}}\right)$ are considered in Table 6 . A simulation of the jth accident course starts with sampling the value $z_{0 j}$ from the pd represented by cdf $F_{0}\left(z_{0} \mid \pi_{0 l}\right)$, where $\pi_{0 l}$ is the value of $\pi_{0}$ sampled in the lth repetition of the outer loop.

\subsubsection{Exceedance of the tolerable value of collision energy}

The model $\boldsymbol{m}_{1}\left(z_{1} \mid \pi_{1}\right)$ is related to a possible exceedance of the tolerable value of collision energy which can lead to an explosion in vehicle A. The phenomenon of exceedance is represented by the random event $E_{1}$ (Fig 5). The model $\boldsymbol{m}_{1}\left(z_{1} \mid \pi_{1}\right)$ is used to decide whether the collision energy is sufficient to damage a container with the explosive charge and trigger off an explosion in vehicle $\mathrm{A}$ as well as to compute a standoff of the explosion (radial distance from explosion centre to location of the structure under analysis).

Model input is represented by the vector $z_{1}=\left(z_{11}, z_{21}, \ldots, z_{71}\right)^{T}$, where $z_{11}$ and $z_{21}$ are the collision coordinates $(\mathrm{m}) ; z_{31}$ and $z_{41}$ are the velocities of vehicles $A$ and $B$ at the collision moment $(\mathrm{m} / \mathrm{s}) ; z_{51}$ and $z_{61}$ are the masses of vehicles $\mathrm{A}$ and $\mathrm{B}(\mathrm{kg}) ; z_{71}$ is the variable expressing the mechanical behaviour of vehicles $\mathrm{A}$ and $\mathrm{B}$ at the collision. Values of arguments of the preceding model $H_{0}\left(z_{0} \mid \pi_{0}, p_{0}\right)$ are assigned to components of $z_{1}$ as follows: $z_{i 1}=z_{i 0}(i=1,2,3,4)$; $z_{51}=6000 \mathrm{~kg}+z_{70} ; z_{61}=z_{50} ; z_{71}=z_{60}$. Here the value $6000 \mathrm{~kg}$ is the mass of vehicle A without the load of explosive.

Model output is given by the vector $\boldsymbol{m}_{1}=\left(m_{11}, m_{21}\right.$, $\left.m_{31}\right)^{T}$, where $m_{11}$ is the standoff $(\mathrm{m}) ; m_{21}$ is the collision energy $\left(\mathrm{kg} \mathrm{m}^{2} / \mathrm{s}^{2}\right) ; m_{31}$ is the difference between the collision energy and a "threshold" energy value which can be tolerated by vehicle A without leading to an explosion $\left(\mathrm{kg} \mathrm{m}^{2} / \mathrm{s}^{2}\right)$.

The structure of $\boldsymbol{m}_{1}\left(z_{1} \mid \pi_{1}\right)$ is as follows:

$$
\boldsymbol{m}_{1}\left(z_{1} \mid \pi_{1}\right)=\left\{\begin{array}{ll}
m_{11}\left(z_{1}\right)= & \left(z_{11}-200\right)^{2}+\left(200-z_{21}\right)^{2} \\
m_{21}\left(z_{1}\right)= & \frac{z_{51} z_{61}}{2\left(z_{51}+z_{61}\right)} \frac{\left(1-z_{71}\right)}{\left(z_{31}+z_{41}\right)^{-2}} \\
m_{31}\left(z_{1} \mid \pi_{1}\right)= & m_{21}\left(z_{1}\right)-\pi^{\prime} ; F_{\Pi^{\prime}}\left(\pi^{\prime} \mid \pi_{1}\right)
\end{array}\right\}
$$

where $\pi^{\prime}$ is the "threshold" energy value $\left(\mathrm{kg} \mathrm{m} / \mathrm{s}^{2}\right)$; $F_{\Pi^{\prime}}\left(\pi^{\prime} \mid \pi_{1}\right)$ is the cdf of a rv. $\Pi^{\prime}$ used to model an aleatory uncertainty in $\pi^{\prime}$. It is assumed that $\left(\Pi^{\prime} \times 10^{-5}\right) \sim N\left(\pi_{11}, \pi_{21}\right)$, where $\pi_{11}$ and $\pi_{21}$ are the mean and variance $\pi_{21}$ of a normal pd, respectively.

Components of the parameter vector 
Table 2. Epistemic probability distributions of the parameters present in the models used to the stochastic simulation of the accident involving an explosion on road in consequence of vehicular collision

\begin{tabular}{|c|c|c|}
\hline Parameter & Distribution & Vector of distribution parameters \\
\hline \multicolumn{3}{|c|}{ Model $H_{0}\left(z_{0} \mid \pi_{0}, p_{0}\right)$} \\
\hline 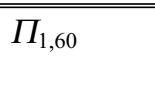 & $\overline{B B e(25,50)}$ & $\begin{array}{l}\text { t } \pi_{\Pi_{1,60}}=(25,50)^{T} \text { (a beta distribution with alpha }=25 \text {, beta }=50 \text {, and } \\
\text { mean }=0,333 \text {; the parent variable } Z_{60} \text { is dimensionless quantity) }\end{array}$ \\
\hline$\Pi_{2,60}$ & $\operatorname{Ex}(140)^{\mathrm{a})}$ & $\begin{array}{l}\qquad \pi_{\Pi_{2,60}}=(140) \text { (an exponential distribution with the mean of } 0,00714 ; \\
\text { the parent variable } Z_{60} \text { is dimensionless quantity) }\end{array}$ \\
\hline \multicolumn{3}{|c|}{ Model $\boldsymbol{m}_{1}\left(z_{1} \mid \pi_{1}\right)$} \\
\hline$\overline{\Pi_{11}}$ & $N(6,1)$ & $\pi_{\Pi_{11}}=\left(6 \mathrm{~kg} \mathrm{~m}^{2} / \mathrm{s}^{2}, 1\left(\mathrm{~kg} \mathrm{~m}^{2} / \mathrm{s}^{2}\right)^{2}\right)^{T}$ \\
\hline$\Pi_{21}^{-1}$ & $G(20,19)^{b)}$ & $\begin{array}{l}\pi_{\Pi_{21}}=\left(20,19\left(\mathrm{~kg} \mathrm{~m}^{2} / \mathrm{s}^{2}\right)^{2}\right)^{T} \text { (the mean, mode and standard deviation } \\
\text { of the uncertain precision } \Pi_{21}^{-1} \text { are equal to } 1,05\left(\mathrm{~kg} \mathrm{~m}^{2} / \mathrm{s}^{2}\right)^{-2} \text {, } \\
1\left(\mathrm{~kg} \mathrm{~m}^{2} / \mathrm{s}^{2}\right)^{-2} \text { and } 0,235\left(\mathrm{~kg} \mathrm{~m}^{2} / \mathrm{s}^{2}\right)^{-2} \text {, respectively) }\end{array}$ \\
\hline \multicolumn{3}{|c|}{ Model $m_{2}\left(z_{2} \mid \pi_{2}\right)$} \\
\hline$\Pi_{12}$ & $N\left(700 \times 10^{3} ; 4,9 \times 10^{9}\right)$ & $\pi_{\Pi_{12}}=\left(700 \times 10^{3} \mathrm{~kg} \mathrm{~m}^{2} / \mathrm{s}^{2} ; 4,9 \times 10^{9}\left(\mathrm{~kg} \mathrm{~m}^{2} / \mathrm{s}^{2}\right)^{2}\right)^{T}$ \\
\hline$\Pi_{22}$ & $N\left(7 \times 10^{4} ; 12,25 \times 10^{6}\right)$ & $\pi_{\Pi_{22}}=\left(7 \times 10^{4} \mathrm{~kg} \mathrm{~m}^{2} / \mathrm{s}^{2} ; 12,25 \times 10^{6}\left(\mathrm{~kg} \mathrm{~m}^{2} / \mathrm{s}^{2}\right)^{2}\right)^{T}$ \\
\hline \multicolumn{3}{|c|}{ Model $\boldsymbol{m}_{3}\left(z_{3} \mid \pi_{3}\right)$} \\
\hline$\Pi_{13}$ & $N\left(-0,125 ; 1,56 \times 10^{-4}\right)$ & $\begin{array}{c}\pi_{\Pi_{13}}=\left(-0,125 ; 1,56 \times 10^{-4}\right)^{T} \quad \text { (the } \text { parent variable } \Pi^{\prime \prime} \quad \text { is } \\
\text { dimensionless quantity) }\end{array}$ \\
\hline$\Pi_{23}$ & $G(15 ; 0,6)$ & $\pi_{\Pi_{23}}=(15 ; 0,6)^{T}$ (the parent variable $\Pi^{\prime \prime}$ is dimensionless quantity) \\
\hline$\Pi_{33}$ & $N\left(-0,159 ; 2,53 \times 10^{-4}\right)$ & $\begin{array}{c}\begin{array}{c}\pi_{\Pi_{33}}=\left(-0,159 ; 2,53 \times 10^{-4}\right)^{T} \\
\text { dimensionless quantity) }\end{array}\end{array}$ \\
\hline$\Pi_{43}$ & $N(15 ; 0,6)$ & $\pi_{\Pi_{43}}=(15 ; 0,6)^{T}$ (the parent variable $\Pi^{\prime \prime \prime}$ is dimensionless quantity) \\
\hline$\Pi_{53}$ & $N\left(0,1 ; 1,0 \times 10^{-4}\right)$ & $\pi_{\Pi_{53}}=\left(0,1 \mathrm{MPa} \mathrm{m} / \mathrm{kg}^{1 / 3} ; 1,0 \times 10^{-4}\left(\mathrm{MPa} \mathrm{m} / \mathrm{kg}^{1 / 3}\right)^{2}\right)^{T}$ \\
\hline$\Pi_{63}$ & $N\left(0,43 ; 1,6 \times 10^{-3}\right)$ & $\pi_{\Pi_{63}}=\left(0,43 \mathrm{MPa} \mathrm{m}{ }^{2} / \mathrm{kg}^{2 / 3} ; 1,6 \times 10^{-3}\left(\mathrm{MPa} \mathrm{m} / \mathrm{kg}^{2 / 3}\right)^{2}\right)^{T}$ \\
\hline$\Pi_{73}$ & $N\left(1,4 ; 2,25 \times 10^{-2}\right)$ & $\pi_{\Pi_{73}}=\left(1,4 \mathrm{MPa} \mathrm{m}^{3} / \mathrm{kg} ; 2,25 \times 10^{-2}\left(\mathrm{MPa} \mathrm{m}^{3} / \mathrm{kg}^{2}\right)^{T}\right.$ \\
\hline$\Pi_{83}$ & $N(6,3 ; 0,36)$ & $\pi_{\Pi_{83}}=\left(6,3 \mathrm{MPa} \mathrm{s} /\left(\mathrm{m} \mathrm{kg}^{2 / 3}\right) ; 0,36\left(\mathrm{MPa} \mathrm{s} /\left(\mathrm{m} \mathrm{kg}^{2 / 3}\right)\right)^{2}\right)^{T}$ \\
\hline
\end{tabular}

$\pi_{1}=\left(\pi_{11}, \pi_{21}\right)^{T}$ are considered to be uncertain in the epistemic sense. Epistemic uncertainty in components of $\pi_{1}$ is expressed by the random vector $\Pi_{1}=\left(\Pi_{11}, \Pi_{21}\right)^{T}$ with cdf

$$
F_{\Pi_{1}}\left(\pi_{1} \mid \pi_{\Pi_{1}}\right)=\prod_{i=1}^{2} F_{\Pi_{i 1}}\left(\pi_{i 1} \mid \pi_{\Pi_{i 1}}\right) .
$$

Epistemic probability distributions of rvs $\Pi_{11}$ and $\Pi_{21}$ are specified in Table 2.

The model component $m_{31}\left(z_{1} \mid \pi_{1}\right)$ is used to decide which of the events $E_{1}$ or $\bar{E}_{1}$ will occur:

$$
\mathbf{1}\left(z_{1 j} \mid \pi_{1 l}\right)=\left\{\begin{array}{ll}
1 & \text { if } m_{31}\left(z_{1 j} \mid \pi_{1 l}\right)-\pi_{j}^{\prime} \geq 0\left(E_{1} \text { occurs }\right) \\
0 & \text { if } m_{31}\left(z_{1 j} \mid \pi_{1 l}\right)-\pi_{j}^{\prime}<0\left(\bar{E}_{1} \text { occurs }\right)
\end{array},\right.
$$

where $z_{1 j}$ and $\pi_{j}^{\prime}$ are the values of $z_{1}$ and $\pi^{\prime}$, respectively, used in the jth repetition of the inner loop. The value $z_{1 j}$ is obtained by sampling from the preceding model $H_{0}\left(z_{0} \mid \pi_{0}, p_{0}\right)$. The vector $\pi_{1 l}$ is a value of parameter vector $\pi_{1}$ sampled from the cdf $F_{\Pi^{\prime}}\left(\pi^{\prime} \mid \pi_{1 l}\right)$ in the lth repetition of the outer loop.
The main assumption underpinning the model $\boldsymbol{m}_{1}\left(z_{1} \mid \pi_{1}\right)$ is that only a frontal collision of vehicles A and $\mathrm{B}$ is possible. This assumption is made for the sake of simplicity.The expression of the frontal collision energy, $m_{21}\left(z_{1}\right)$, was adopted from [24]. The normal pd of $\Pi^{\prime}$ was chosen hypothetically. Assigning and updating the pd represented by cdf $F_{\Pi_{1}}\left(\pi_{1} \mid \pi_{\Pi_{1}}\right)$ are considered in Table 6.

\subsubsection{Explosion of the charge in vehicle}

An occurrence of explosion of the charge in vehicle $\mathrm{A}$ is represented by the random event $E_{2}$ (Fig 5). The model $m_{2}\left(z_{2} \mid \pi_{2}\right)$ serves for a simulation of the occurrence or non-occurrence of $E_{2}$. In particular, the model $m_{2}\left(z_{2} \mid \pi_{2}\right)$ is used to decide whether the collision energy when exceeds the safe "threshold" value will cause the explosion in vehicle A.

Model input is represented by the collision energy $z_{2}\left(\mathrm{~kg} \mathrm{~m}^{2} / \mathrm{s}^{2}\right)$; values of $z_{2}$ are assigned by $z_{2}=m_{21}\left(z_{1}\right)$. 
Model output is an auxiliary dimensionless variable $m_{2}$ used in the decision rule related to the present model. The structure of the model is

$$
m_{2}\left(z_{2} \mid \pi_{2}\right):=\left\{m_{2}=F_{12}^{-1}(u \mid 1, \pi), \pi=F_{22}\left(z_{2} \mid \pi_{2}\right)\right\},
$$

where where $F_{12}^{-1}(u \mid 1, \pi)$ is the inverse cdf of a binomial pd with parameters 1 and $\pi$ and argument $u \in] 0,1[$; $F_{22}\left(z_{2} \mid \pi_{2}\right)$ is the fragility function (cdf of a normal pd with the parameter vector $\pi_{2}$ ); the parameter $\pi$ models an explosion probability, and the output variable $m_{2}$ models an occurrence or non-occurrence of the explosion; $m_{2}$ can take on values 1 (event $E_{2}$ occurs) or 0 (event $\bar{E}_{2}$ occurs) (Fig 5). The inverse cdf $F_{12}^{-1}(u \mid 1, \pi)$ is used to suggest that the values $m_{2}\left(z_{2 j} \mid \pi_{2 l}\right)$ of the variable $m_{2}$ are simulated by applying the inverse transform method (eg, [25]).

Components of the parameter vector $\pi_{2}$ are considered to be uncertain in the epistemic sense. Epistemic uncertainty in components of $\pi_{2}$ is expressed by the random vector $\Pi_{2}=\left(\Pi_{12}, \Pi_{22}\right)^{T}$ with cdf

$$
F_{\Pi_{2}}\left(\pi_{2} \mid \pi_{\Pi_{2}}\right)=\prod_{i=1}^{2} F_{\Pi_{i 2}}\left(\pi_{i 2} \mid \pi_{\Pi_{i 2}}\right) .
$$

Epistemic probability distributions of rvs $\Pi_{12}$ and $\Pi_{22}$ are specified in Table 2.

The value $m_{2}\left(z_{2 j} \mid \pi_{2 l}\right)$ is used to decide which of the events $E_{2}$ or $\bar{E}_{2}$ will occur:

$$
\mathbf{1}\left(z_{2 j} \mid \pi_{2 l}\right)=\left\{\begin{array}{ll}
1 & \text { if } F_{12}^{-1}\left(u_{j} \mid 1, F_{22}\left(z_{2 j} \mid \pi_{2 l}\right)\right)=1\left(E_{2} \text { occurs }\right) \\
0 & \text { if } F_{12}^{-1}\left(u_{j} \mid 1, F_{22}\left(z_{2 j} \mid \pi_{2 l}\right)\right)=0\left(\bar{E}_{2} \text { occurs }\right)
\end{array},\right.
$$

where $z_{2 j}$ is the collision energy value computed in the $j$ th repetition of the inner loop; $u_{j}$ is the value of $u$ sampled from $U(0,1)$ in the jth repetition; and $\pi_{2 l}$ is the value the parameter vector $\pi_{2}$ sampled in the $l$ th repetition of the outer loop from the pd represented by cdf $F_{\Pi_{2}}\left(\pi_{2} \mid \pi_{\Pi_{2}}\right)$.

The model $m_{2}\left(z_{2} \mid \pi_{2}\right)$ is underpinned by the assumption that an exceedance of the "threshold" energy value used in the model $\boldsymbol{m}_{1}\left(z_{1} \mid \pi_{1}\right)$ does not necessarily cause an explosion of the charge in vehicle A. However, the probability of such an explosion, $\pi$, is the higher, the larger is the collision energy $z_{2}$. The cdf of a normal pd was chosen as the fragility function $F_{22}\left(z_{2} \mid \pi_{2}\right)$ hypothetically. Assigning and updating the pd represented by cdf $F_{\Pi_{2}}\left(\pi_{2} \mid \pi_{\Pi_{2}}\right)$ are considered in Table 6 .

\subsubsection{Predicting characteristics of the incident blast wave}

The model $\boldsymbol{m}_{3}\left(z_{3} \mid \pi_{3}\right)$ describes the incident blast wave approaching the structural system under analysis. This model is used to relate the charge mass and standoff to characteristics of incident blast wave (peak positive overpressure and positive impulse represented by the vector $\boldsymbol{x}$ ).
Model input is represented by the vector $z_{3}=\left(z_{13}, z_{23}\right)^{T}$, where $z_{13}$ and $z_{23}$ are the charge mass $(\mathrm{kg})$ and standoff $(\mathrm{m})$, respectively (Fig 4). Values of $z_{13}$ and $z_{23}$ are assigned by the expressions $z_{13}=z_{70}$ and $z_{23}=m_{11}\left(z_{1}\right)$. Model output is given by the vector $\boldsymbol{m}_{3}=\left(m_{13}, m_{23}\right)^{T}$, where $m_{13}$ is the peak positive overpressure $(\mathrm{MPa}) ; m_{23}$ is the positive impulse $\left(\mathrm{MPa} \mathrm{s} / \mathrm{m}^{2}\right)$. In terms of the notation used in Sec 3.2, $x_{1}=m_{13}$ and $x_{2}=m_{23}$ (Fig 2).

The model $\boldsymbol{m}_{3}\left(z_{3} \mid \pi_{3}\right)$ has the following structure:

$$
\begin{gathered}
m_{13}\left(z_{3} \mid \pi_{3}\right)=\left\{\begin{array}{l}
m_{13}=\pi^{\prime \prime} m_{13}^{\prime}\left(z_{3} \mid \pi_{53}, \pi_{63}, \pi_{73}\right) \\
F_{\ln \Pi \prime}\left(\ln \pi^{\prime \prime} \mid \pi_{13}, \pi_{23}\right)
\end{array}\right\}, \\
m_{23}\left(z_{3} \mid \pi_{3}\right)=\left\{\begin{array}{l}
m_{23}=\pi^{\prime \prime \prime} m_{23}^{\prime}\left(z_{3} \mid \pi_{83}\right) \\
F_{\ln \Pi^{\prime \prime \prime}}\left(\ln \pi^{\prime \prime \prime} \mid \pi_{33}, \pi_{43}\right)
\end{array}\right\},
\end{gathered}
$$

with

$$
\begin{gathered}
m_{13}^{\prime}\left(z_{3} \mid \pi_{53}, \pi_{63}, \pi_{73}\right)=\pi_{53} \frac{z_{13}^{1 / 3}}{z_{23}}+\pi_{63} \frac{z_{13}^{2 / 3}}{z_{23}^{2}}+\pi_{73} \frac{z_{13}}{z_{23}^{3}} \\
m_{23}^{\prime}\left(z_{3} \mid \pi_{83}\right)=\pi_{83} \frac{z_{13}^{2 / 3}}{z_{23}}
\end{gathered}
$$

where $\pi^{\prime \prime}$ and $\pi^{\prime \prime \prime}$ are the dimensionless adjustment factors (relative overpressure and relative impulse of the explosive in vehicle A compared to an equivalent weight of TNT explosive); $m_{13}^{\prime}\left(z_{3} \mid \pi_{53}, \pi_{63}, \pi_{73}\right)$ and $m_{23}^{\prime}\left(z_{3} \mid \pi_{83}\right)$ are the models relating components of $z_{3}$ to the overpressure and impulse of a TNT explosion, respectively; $F_{\ln \Pi^{\prime \prime}}\left(\ln \pi^{\prime \prime} \mid \pi_{13}, \pi_{23}\right)$ and $F_{\ln \Pi^{\prime \prime \prime}}\left(\ln \pi^{\prime \prime \prime} \mid \pi_{33}, \pi_{43}\right)$ are the cdfs expressing an aleatory uncertainty in logarithms of the factors $\pi^{\prime \prime}$ and $\pi^{\prime \prime \prime}$. The rvs $\Pi^{\prime \prime}$ and $\Pi^{\prime \prime \prime}$ are used to model the aleatory uncertainty: $\ln \Pi^{\prime \prime} \sim$ $N\left(\pi_{13}, \pi_{23}\right)$ (a normal distribution with an uncertain mean $\pi_{13}$ and variance $\left.\pi_{23}\right)$; $\ln \Pi^{\prime \prime \prime} \sim N\left(\pi_{33}, \pi_{43}\right)$ (a normal distribution with an uncertain mean $\pi_{33}$ and variance $\left.\pi_{43}\right)$.

Components of the parameter vector $\pi_{3}$ (distribution parameters $\pi_{13}, \pi_{23}, \pi_{33}, \pi_{43}$ and regression parameters $\pi_{53}, \pi_{63}, \pi_{73}, \pi_{83}$ ) are considered to be uncertain in the epistemic sense. Epistemic uncertainty in components of $\pi_{3}$ is expressed by the random vector $\Pi_{3}=\left(\Pi_{13}, \Pi_{23}, \ldots, \Pi_{83}\right)^{T}$ with cdf

$$
F_{\Pi_{3}}\left(\pi_{3} \mid \pi_{\Pi_{3}}\right)=\prod_{i=1}^{8} F_{\Pi_{i 3}}\left(\pi_{i 3} \mid \pi_{\Pi_{i 3}}\right) .
$$

Epistemic probability distributions of components of the vector $\Pi_{3}$ are specified in Table 2 .

The models $m_{13}^{\prime}\left(z_{3} \mid \pi_{53}, \pi_{63}, \pi_{73}\right)$ and $m_{23}^{\prime}\left(z_{3} \mid \pi_{83}\right)$ were adopted from [26]. The lognormal pds of the random adjustment factors $\Pi^{\prime \prime}$ and $\Pi^{\prime \prime \prime}$ were chosen hypothetically. Deterministic values of these factors suitable to an adjustment of the TNT models $m_{13}^{\prime}\left(z_{3} \mid \pi_{53}, \pi_{63}, \pi_{73}\right)$ and $m_{23}^{\prime}\left(z_{3} \mid \pi_{83}\right)$ can be found, eg, in [27]. Assigning and updating the p.d. represented by cdf $F_{\Pi_{3}}\left(\pi_{3} \mid \pi_{\Pi_{3}}\right)$ are considered in Table 6. 


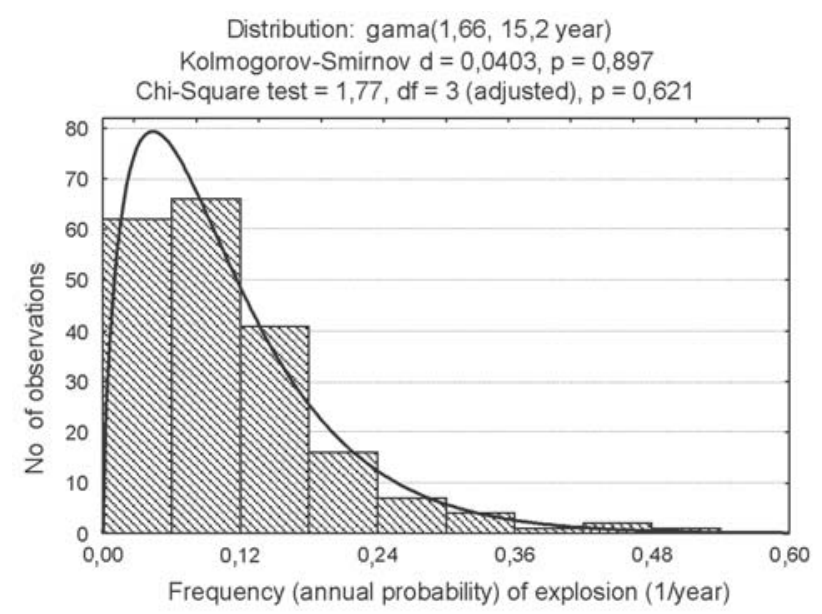

Fig 6. Fitting a gamma distribution used to model the epistemic uncertainty in the explosion frequency $p_{a}$

\subsection{Fitting a probabilistic model for the explosive action}

An accident simulation with $n_{p}=200$ and $n_{0}=1000$ generated a sample of frequencies, $p_{0 l} n_{a l} / n_{0}(l=1,2$, $\ldots, 200)$, and samples of action characteristics, $\mathbf{x}_{l} \quad(l=1$, $2, \ldots, 200)$. Descriptive measures of the samples $n_{a l}$ $(l=1,2, \ldots, 200)$ and $p_{0 l} n_{a l} / n_{0}(l=1,2, \ldots, 200)$ are given in Table 3 . A gamma distribution with the parameter vector $\pi_{a}=(1,66 ; 15,2$ year $)$ can be fitted to the sample $p_{0 l} n_{a l} / n_{0}(l=1,2, \ldots, 200)$ as cdf $F_{P_{a}}\left(p_{a} \mid \pi_{a}\right)$ (Fig 6). This gamma distribution expresses the epistemic uncertainty in the explosion frequency $p_{a}$.

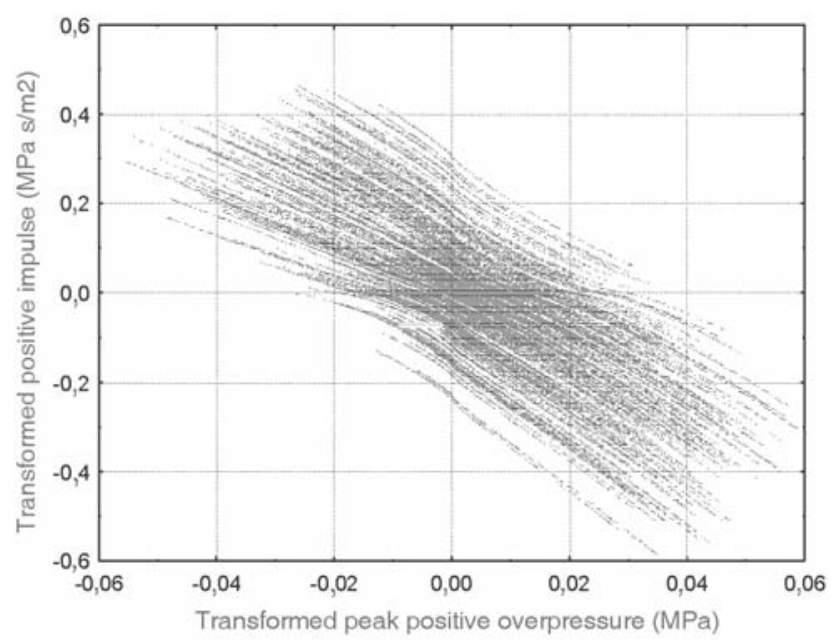

Fig 7. Scatter diagram containing transformed values of peak positive overpressure $y_{1 j}$ and positive impulse $y_{2 j}$ drawn for the second cluster $\mathbf{y}_{2}^{\prime}$

The cdfs $F_{\boldsymbol{X}_{i}}\left(\boldsymbol{x} \mid \pi_{\boldsymbol{x}_{i}}\right)(i=1,2,3)$ can be fitted by applying the heuristic procedure suggested in Sec 3.2.3. This procedure requires to preset number $n$ and probabilistic weights $p_{i}(i=1,2, \ldots, n)$ in advance. In the present case study, it is assumed that $n=3$ and $p_{1}=$ $p_{3}=0,25, p_{2}=0,5$. With these values, the samples $\mathbf{x}_{l}$ $(l=1,2, \ldots, 200)$ were grouped in three clusters $\mathbf{x}_{i}^{\prime}$ $(i=1,2,3)$ with descriptive measures given in Table 3 .

A transformation of the clusters $\mathbf{x}_{i}^{\prime}(i=1,2,3)$ is necessary to allow fitting a widely known bivariate pd. For instance, the intuitively chosen transformations given

Table 3. Descriptive measures of samples related to the accidental explosion on road

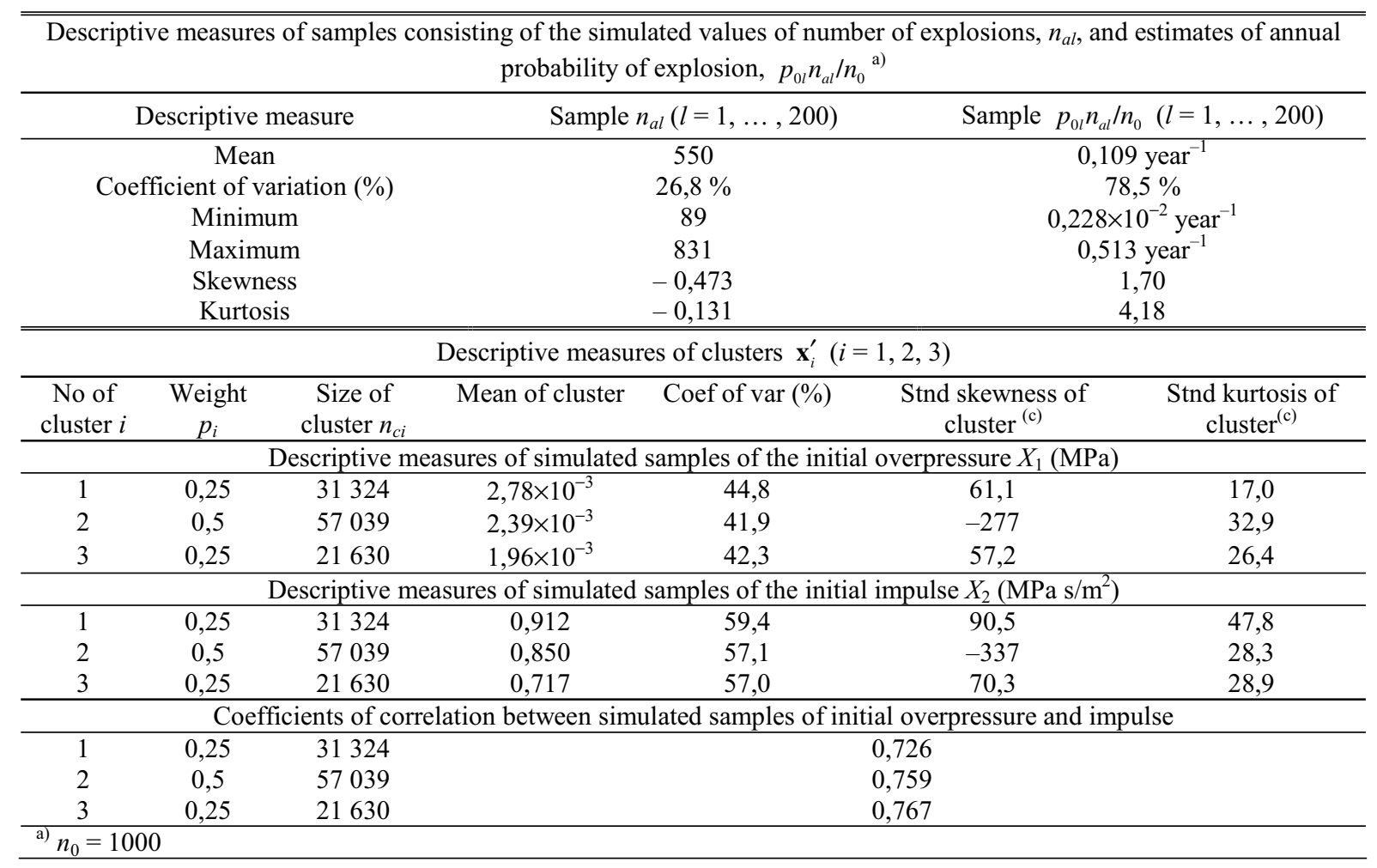


in Table 4 yield another three clusters $\mathbf{y}_{i}^{\prime}(i=1,2,3)$. A scatter diagram of the second cluster $\mathbf{y}_{2}^{\prime}$ is shown in Fig 7. The size of the second cluster, $n_{c 2}$, (number of points in the diagram given in Fig 7) is equal to 57039 (Table 3). Scatter diagrams of the remaining two clusters are similar. Descriptive measures of the clusters $\mathbf{y}_{i}^{\prime}$ $(i=1,2,3)$ suggest that the pairs of rvs

$$
\begin{aligned}
& \left(Y_{1 i}, Y_{2 i}\right)^{T}= \\
& =\left(\operatorname{sign}\left(\lg \left(-\lg X_{1}\right)-\alpha_{1 i} \bar{x}_{1 i 2 L}\right)\left|\lg \left(-\lg X_{1}\right)-\alpha_{1 i} \bar{x}_{1 i 2 L}\right|^{\beta_{1 i}},\right. \\
& \left.\operatorname{sign}\left(\lg \left(-\lg X_{2}\right)-\alpha_{2 i} \bar{x}_{2 i L}\right)\left|\lg \left(-\lg X_{2}\right)-\alpha_{2 i} \bar{x}_{2 i L}\right|^{\beta_{2 i}}\right) \\
& \quad(i=1,2,3)
\end{aligned}
$$

can be considered to be approximately normally distributed, correlated rvs. A bivariate normal distribution can be fitted to each of the clusters $\mathbf{y}_{i}^{\prime}(i=1,2,3)$. Parameters of this distribution can be derived from descriptive measures given in Table 4. In such a case the general expression of the action model $H_{X}(\boldsymbol{x})$ can be reformulated for the vectors $\boldsymbol{Y}_{i}=\left(Y_{1 i}, Y_{2 i}\right)^{T}(i=1,2,3)$, that is, for the transformed peak positive overpressure and transformed positive impulse and represented as

$$
\begin{gathered}
H_{Y}(\boldsymbol{y}):=\left\{F_{P_{a}}\left(p_{a} \mid \boldsymbol{\pi}_{a}\right),\left(F_{Y_{1}}\left(\boldsymbol{y} \mid \mu_{y_{1}}, \Sigma_{y_{1}}\right), 0,25\right),\right. \\
\left.\left(F_{Y_{2}}\left(\boldsymbol{y} \mid \mu_{y_{2}}, \Sigma_{y_{2}}\right), 0,5\right),\left(F_{Y_{3}}\left(\boldsymbol{y} \mid \mu_{y_{3}}, \Sigma_{y_{3}}\right), 0,25\right)\right\},
\end{gathered}
$$

where $F_{P_{a}}\left(p_{a} \mid \pi_{a}\right)$ is cdf of the gamma distribution with the parameter vector $\pi_{a}=(1,66 ; 15,2$ year $)$; $F_{\boldsymbol{Y}_{i}}\left(\boldsymbol{y} \mid \mu_{\boldsymbol{y}_{i}}, \Sigma_{y_{i}}\right)(i=1,2,3)$ are cdfs of a bivariate normal distribution with the mean vectors $\mu_{y_{i}}$ and covariance matrices $\Sigma_{y_{i}}$ given in Table 5 .

The action model $H_{\boldsymbol{Y}}(\boldsymbol{y})$ defined by Eq 2 can be considered to be a result of uncertainty propagation. The "lower-level" aleatory uncertainties in characteristics of the initiating event $E_{0}$ are transformed into the "higherlevel" aleatory uncertainties in the peak positive overpressure $x_{1}$ and positive impulse $x_{2}$. The "lower-level" uncertainties are quantified by c.d.f. $F_{0}\left(z_{0} \mid \pi_{0}\right)$, whereas the "higher-level" uncertainties are expressed by the family of cdfs $F_{\boldsymbol{Y}_{i}}\left(\boldsymbol{y} \mid \mu_{\boldsymbol{y}_{i}}, \boldsymbol{\Sigma}_{\boldsymbol{y}_{i}}\right) \quad(i=1,2,3)$. At the same time, the "lower-level" epistemic uncertainties related to

\begin{tabular}{|c|c|c|c|c|c|c|c|}
\hline \multicolumn{8}{|c|}{ Descriptive measure/characteristic of cluster } \\
\hline $\begin{array}{l}\text { No of } \\
\text { cluster } i\end{array}$ & $\bar{x}_{k i 2 L}$ & $\bar{x}_{k i L}$ & $\alpha_{k i} / \beta_{k i}$ & $\begin{array}{c}\text { Mean of } \\
\text { cluster }\end{array}$ & $\begin{array}{l}\text { Std dev of } \\
\text { cluster }\end{array}$ & $\begin{array}{c}\text { Stnd skewof } \\
\text { cluster }^{\text {b) }}\end{array}$ & $\begin{array}{c}\text { Stnd kurtosis of } \\
\text { cluster }^{\text {b }}\end{array}$ \\
\hline \multicolumn{8}{|c|}{ Descriptive measures of transformed samples of the initial overpressure (MPa), $k=1$} \\
\hline 1 & 0,414 & - & $1,011 / 1,12$ & $-3,15 \times 10^{-3}$ & 0,0231 & 1,084 & 0,0908 \\
\hline 2 & 0,424 & - & $0,984 / 1,165$ & $4,00 \times 10^{-3}$ & 0,0177 & 0,119 & 0,378 \\
\hline 3 & 0,437 & - & $0,983 / 1,159$ & $4,46 \times 10^{-3}$ & 0,0175 & $-0,874$ & $-0,158$ \\
\hline \multicolumn{8}{|c|}{ Descriptive measures of transformed samples of the initial impulse $\left(\mathrm{MPa} \mathrm{s} / \mathrm{m}^{2}\right), k=2$} \\
\hline 1 & - & $-0,111$ & $0,8 / 1,22$ & $-1,67 \times 10^{-2}$ & 0,197 & 0,348 & $-0,0763$ \\
\hline 2 & - & $-0,137$ & $0,828 / 1,315$ & $-1,52 \times 10^{-2}$ & 0,170 & $-1,188$ & 0,144 \\
\hline 3 & - & $-0,210$ & $0,81 / 1,34$ & $-2,63 \times 10^{-2}$ & 0,163 & 0,562 & 0,247 \\
\hline \multicolumn{8}{|c|}{ Coefficients of correlation between transformed samples of overpressure and impulse } \\
\hline 1 & \multicolumn{7}{|c|}{$-0,731$} \\
\hline 2 & \multicolumn{7}{|c|}{$-0,770$} \\
\hline 3 & \multicolumn{7}{|c|}{$-0,796$} \\
\hline
\end{tabular}
the models $H_{0}\left(z_{0} \mid \pi_{0}, p_{0}\right), \boldsymbol{m}_{1}\left(z_{1} \mid \pi_{1}\right)$, and $m_{2}\left(z_{2} \mid \pi_{2}\right)$ and $\boldsymbol{m}_{3}\left(z_{3} \mid \pi_{3}\right)$ are transformed into the "higher-level" distributions of epistemic uncertainty which appear in the expression of $H_{\boldsymbol{Y}}(\boldsymbol{y})$, namely, a continuous distribution

Table 4. Descriptive measures of the clusters $\mathbf{y}_{i}^{\prime}$ obtained by transforming the initial clusters $\mathbf{x}_{i}^{\prime}(i=1,2,3)^{\mathrm{a})}$

a) The clusters $\mathbf{y}_{i}^{\prime}(i=1,2,3)$ are obtained from clusters $\mathbf{x}_{i}^{\prime}(i=1,2,3)$ by the transformations $y_{1 j}=\operatorname{sign}\left(\lg \left(-\lg x_{1 j}\right)-\alpha_{1 i} \bar{x}_{1 i 2 L}\right)\left|\lg \left(-\lg x_{1 j}\right)-\alpha_{1 i} \bar{x}_{1 i 2 L}\right|^{\beta_{1 i}}$ and $y_{2 j}=\operatorname{sign}\left(\lg x_{2 j}-\alpha_{2 i} \bar{x}_{2 i L}\right)\left|\lg x_{2 j}-\alpha_{2 i} \bar{x}_{2 i L}\right|^{\beta_{2 i}}$

with $\bar{x}_{k i L}=n_{c i}^{-1} \sum_{j=1}^{n_{c i}} \lg x_{k i j}$ and $\bar{x}_{k i 2 L}=n_{c i}^{-1} \sum_{j=1}^{n_{c i}} \lg \left(-\lg x_{k i j}\right)$, where $x_{k i j}$ is the simulated value of the $k$ th action characteristic treated as the $j$ th element of the $i$ th cluster; lg denotes the common logarithm

b) "Stnd"= Standardised, "Std dev" = Standard deviation, "skew"= skewness

Table 5. Parameters of cdfs $F_{Y_{i}}\left(\boldsymbol{y} \mid \mu_{y_{i}}, \Sigma_{y_{i}}\right)(i=1,2,3)$ present in the expression of the action model $H_{Y}(\boldsymbol{y})(\mathrm{Eq}(2))$ a)

\begin{tabular}{ccc}
\hline & $\mu_{y_{i}}$ & $\left.\Sigma_{y_{i}}=\operatorname{diag}\left(\sigma_{y_{i}}\right)\left(\begin{array}{cc}1 & \rho_{i} \\
\rho_{i} & 1\end{array}\right) \operatorname{diag}\left(\sigma_{y_{i}}\right) \mathrm{b}\right)$ \\
\hline 1 & $\left(-3,15 \times 10^{-3} \mathrm{MPa},-1,67 \times 10^{-2} \mathrm{MPa} \mathrm{s} / \mathrm{m}^{2}\right)^{T}$ & $\sigma_{y_{1}}=\left(0,0231 \mathrm{MPa}, 0,197 \mathrm{MPa} \mathrm{s} / \mathrm{m}^{2}\right), \rho_{1}=-0,731$ \\
2 & $\left(4,00 \times 10^{-3} \mathrm{MPa},-1,52 \times 10^{-2} \mathrm{MPa} \mathrm{s} / \mathrm{m}^{2}\right)^{T}$ & $\sigma_{y_{2}}=\left(0,0177 \mathrm{MPa}, 0,170 \mathrm{MPa} \mathrm{s} / \mathrm{m}^{2}\right), \rho_{2}=-0,770$ \\
3 & $\left(4,46 \times 10^{-3} \mathrm{MPa},-2,63 \times 10^{-2} \mathrm{MPa} \mathrm{s} / \mathrm{m}^{2}\right)^{T}$ & $\sigma_{y_{3}}=\left(0,0175 \mathrm{MPa}, 0,163 \mathrm{MPa} \mathrm{s} / \mathrm{m}^{2}\right), \rho_{3}=-0,796$ \\
\hline
\end{tabular}

a) Values of the parameters were derived from the descriptive measures given in Table 3.

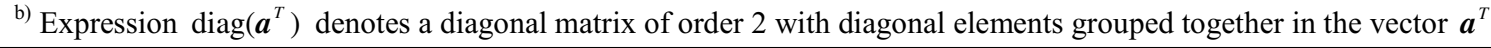


represented by cdf $F_{P_{a}}\left(p_{a} \mid \pi_{a}\right)$ and a discrete distribution represented by the probabilistic weights $p_{1}=p_{3}=0,25, p_{2}=0,5$.

The case study described in this section is illustrative and input information represented by the probability distributions related to the models $H_{0}\left(z_{0} \mid \pi_{0}, p_{0}\right)$, $\boldsymbol{m}_{1}\left(z_{1} \mid \pi_{1}\right)$, and $m_{2}\left(z_{2} \mid \pi_{2}\right)$ is hypothetical. In actual practice the selection of $H_{\boldsymbol{Y}}(\boldsymbol{y})$ would require a collection of available hard data and elicitation of expert judgements. On the other hand, the present case study may be considered to be a practical intermediate result. It provides a list of physical variables and model parameters for which data and judgements are to be obtained in order to select probabilistic models used as input of the model selection problem. The collection of real world information was beyond the scope of this case study.

\section{Expert judgement in Bayesian predicting acciden- tal actions}

\subsection{Need for expert judgment}

A need for expert judgement, which can be expressed mathematically in CBA framework as "lowerlevel" (input) information suitable for quantifying uncertainties related to AAs, arises from the fact that these actions are typically rare events backed by scarce historical data. The action model $H_{X}(\boldsymbol{x})$ defined by Eq (1) reflects uncertainties expressed by the set of "lower-level" models $\boldsymbol{\Xi}_{1}$ and $\boldsymbol{\Xi}_{2}$ described in Sec 3.2.2. Let, for brevity, elements of these two sets group into one set $\boldsymbol{\Xi}$ defined as

$$
\begin{aligned}
\Xi:= & \left\{F_{P_{0}}\left(p_{0} \mid \pi_{P_{0}}\right), F_{0}\left(z_{0} \mid \pi_{0}\right),\right. \\
& \boldsymbol{m}_{k}\left(z_{k} \mid \pi_{k}\right),\left(k=1,2, \ldots, n_{k}\right) \\
& \left.F_{\Pi_{k}}\left(\pi_{k} \mid \pi_{\Pi_{k}}\right)\left(k=0,1,2, \ldots, n_{k}\right)\right\} .
\end{aligned}
$$

Given the model set $\boldsymbol{\Xi}$, the selection of $H_{X}(\boldsymbol{x})$ amounts to an uncertainty propagation by means of the simulation-based procedure proposed in Sec 3.2. The main technical requirement for an application of this procedure is a possibility to sample (generate) sets of values $\left\{p_{0 l}, \boldsymbol{z}_{0 j}, \boldsymbol{\pi}_{k l}\left(k=0,1,2, \ldots, n_{k}\right)\right\}$ from corresponding pds represented by elements of $\boldsymbol{\Xi}$. In most cases this requirement is easy to meet (eg, the book [25] for techniques of random variate generation).

According to the model classification used in QRA, models $\boldsymbol{m}_{k}\left(z_{k} \mid \pi_{k}\right) \quad\left(k=1,2, \ldots, n_{k}\right)$ can be considered to be process models, frequency $p_{0}$ and cdfs $H_{0}\left(z_{0} \mid \pi_{0}, p_{0}\right), F_{0}\left(z_{0} \mid \pi_{0}\right)$ and $F_{\Pi_{k}}\left(\pi_{k} \mid \pi_{\Pi_{k}}\right) \quad(k=0,1$, $2, \ldots, n_{k}$ ) belong to stochastic models, and the event tree underlying the model set $\boldsymbol{\Xi}$ falls into the category of decomposition models $[20,28]$. The structure of $\boldsymbol{\Xi}$ depends mainly on the available knowledge about physical phenomena leading to $O A A$ (event tree path $E_{0}, E_{1}$, $\ldots, E_{n_{k}-1}$, Fig 2). A part of this knowledge should be the process models $\boldsymbol{m}_{k}\left(z_{k} \mid \pi_{k}\right)\left(k=1,2, \ldots, n_{k}\right)$ which describe the physical phenomena and are a prerequisite for an application of the simulation-based procedure described in Sec 3.2. Another part of the knowledge should be information which allows assigning and updating the stochastic models included in $\boldsymbol{\Xi}$. This information may consist of available hard data and expert judgements. In some instances expert judgements can represent the only source of information for specifying elements of $\boldsymbol{\Xi}$.

Expert judgement can be incorporated in modelling AAs by applying organisational and mathematical methods developed in the field of QRA. These methods determine choice of experts, formal elicitation of expert opinions as well as quantification and combination of the opinions $[8,20,28]$. It is beyond the scope of this paper to give a detailed review of those QRA methods which allow the use of expert judgement for specifying elements of $\boldsymbol{\Xi}$. The following discussion seeks to capture only essential methods and to illustrate their application in the context of the case study described in Sec 4. The discussion given in the reminder of Sec 5 covers the use of expert judgement for assigning the stochastic models (probabilities and pds) and quantifying uncertainties related to the process models included in $\boldsymbol{\Xi}$.

\subsection{Expert judgement in assigning probabilities and probability distributions}

Formal means applied in QRA to combining expert judgement with available hard data are provided by the Bayesian statistical theory $[10,28]$. In CBA, elements of this theory are used for updating expert opinions expressed as prior (posterior) distributions of epistemic uncertainty when new information becomes available. These distributions are related to input parameters of such QRA models as event trees and fault trees. Bayesian updating schemes can be used for combining probabilities and pds subjectively assessed by experts [29].

A number of methods for constructing prior distributions (priors) have been proposed in the Bayesian statistical theory, eg, [30, 31]. Certain of them can be used for constructing prior distributions in situations where relevant hard data are sparse or where such data are not available and constructing priors has to be based on other forms of information. Some effort has been directed towards the use of expert judgement for determining the likelihood function which is an integral part of Bayesian updating schemes [29, 32, 33, 34]. Formal methods for eliciting probabilities and pds from experts have been extensively developed in the field of QRA $[29,35,36]$. Many practical situations covered by the above-mentioned methods can be encountered when modelling AAs. These methods can be applied to specifying the epistemic uncertainty measures included in the model set $\boldsymbol{\Xi}$.

Constructing and updating an uncertainty distribution defined in the entire model and parameter space of a QRA problem based on CBA is considered to be an impracticable task [37]. A practical way out of this situ- 
ation is to assign marginal uncertainty distributions only to some selected parameters and models as is done in the case study described in Sec 4 . The cdfs included in the model set $\boldsymbol{\Xi}$ quantify epistemic uncertainties only in selected parameters which are modelled as independent rvs As a result, distributions of epistemic uncertainty represented by the action model (2) reflect only the uncertainties expressed by these marginal cdfs.

Specifying the stochastic models belonging to $\Xi$ is to a large degree a case-specific task. It is determined by available knowledge (general information on the physical phenomena related to $E_{k} \mathrm{~s}$, relevant hard data on $E_{k} \mathrm{~s}$, and expert judgements) as well as procedures suitable for assigning and updating the stochastic models of $\boldsymbol{\Xi}$. Case-specific sets of such procedures can be regarded as integral parts of individual AA modelling problems. Table 6 contains methodological ("how-to-do" and "where-to-find") descriptions of the procedures which can be applied to assigning and updating the stochastic models used in the case study given in Sec 4.

\subsection{Expert judgement in modelling physical phenomena}

An incorporation of expert judgement in modelling physical phenomena, which can escalate into $O A A$, is to a large degree a problem that can be solved by QRA means deve+loped for a model uncertainty analysis and closely linked to an expert opinion use, see, for instance, relevant bibliography in USNRC Regulatory Guide [38]. The meaning of model uncertainty and the role of expert judgement in quantifying this uncertainty under the CBA format are discussed by Nilsen and Aven [39].

In this paper, expert judgements related to the models $\boldsymbol{m}_{k}\left(\boldsymbol{z}_{\boldsymbol{k}} \mid \boldsymbol{\pi}_{k}\right)$ are expressed by cdfs $F_{\Pi_{k}}\left(\pi_{k} \mid \pi_{\Pi_{k}}\right)$, see the description of the model pairs $\left\{\boldsymbol{m}_{k}\left(z_{\boldsymbol{k}} \mid \boldsymbol{\pi}_{k}\right)\right.$, $\left.F_{\Pi_{k}}\left(\pi_{k} \mid \pi_{\Pi_{k}}\right)\right\}$ in Sec 3.2.2. Uncertainty in the models $\boldsymbol{m}_{k}\left(z_{\boldsymbol{k}} \mid \boldsymbol{\pi}_{k}\right)$ is treated as parameter uncertainty. Expert judgements represented by $\operatorname{cdfs} F_{\Pi_{k}}\left(\pi_{k} \mid \pi_{\Pi_{k}}\right)$ can be assigned and updated within the Bayesian framework discussed in the previous section.

QRA leaves room for describing a physical phenomenon lying behind the event $E_{k}$ by a plural model

$$
\left\{\boldsymbol{m}_{e k}\left(\boldsymbol{z}_{e k} \mid \pi_{e k}\right), F_{\Pi_{e k}}\left(\boldsymbol{\pi}_{e k} \mid \pi_{\Pi_{e k}}\right)\right\}\left(e=1,2, \ldots, n_{e} ; n_{e}>1\right)
$$

(a set of $n_{e}$ plausible process models $\boldsymbol{m}_{e k}\left(z_{e k} \mid \pi_{e k}\right)$ with individual input and parameter vectors, $z_{e k}$ and $\pi_{e k}$, as well as individual epistemic cdfs $F_{\Pi_{e k}}\left(\pi_{e k} \mid \pi_{\Pi_{e k}}\right)$, eg, [10]. The plural model can be used instead of the single model $\left\{\boldsymbol{m}_{k}\left(z_{k} \mid \pi_{k}\right), F_{\Pi_{k}}\left(\pi_{k} \mid \pi_{\Pi_{k}}\right)\right\}$ in cases when the phenomenon related to $E_{k}$ can be described by several alternative models $\boldsymbol{m}_{e k}\left(\boldsymbol{z}_{e k} \mid \pi_{e k}\right)$ and none of these models can be justifiably selected over others.

A need for plural models stems from a model validation problem which is frequently encountered in QRA. The methodology of QRA accepts using empirically invalidated models because QRA models and QRA itself are viewed as decision policy tools, not as tools for determining truth $[28,42]$. A validity of the plausible models $\boldsymbol{m}_{e k}\left(\boldsymbol{z}_{e k} \mid \boldsymbol{\pi}_{e k}\right)$ is expressed by the experts' (epistemic) probabilities $p_{e}$ that corresponding models are correct, where $\sum_{e=1}^{n_{e}} p_{e}=1$. The epistemic uncertainty measures $p_{e}$ and $F_{\Pi_{e k}}\left(\pi_{e k} \mid \pi_{\Pi_{e k}}\right)$ can be averaged out to obtain an unconditional deterministic plural model output, $\boldsymbol{m}_{k}\left(\mathbf{z}_{k}\right)$, or, alternatively, a cdf $F_{\boldsymbol{M}_{k}}\left(\boldsymbol{m}_{k} \mid \mathbf{z}_{k}\right)$ expressing an aleatory uncertainty in this output:

- if the output vectors $\boldsymbol{m}_{e k}$ are deterministic, then:

Ouput of the plural vector $=$ deterministic vector $\boldsymbol{m}_{k}\left(z_{k}\right)$

$=\sum_{e=1}^{n_{e}} p_{e} \int_{\text {all } \pi_{e k}} \boldsymbol{m}_{e k}\left(z_{e k} \mid \pi_{e k}\right) \mathrm{d} F_{\Pi_{e k}}\left(\pi_{e k} \mid \pi_{\Pi_{e k}}\right) ;$

- if $\boldsymbol{m}_{e k} \mathrm{~s}$ can be expressed as random vectors $\boldsymbol{M}_{e k}$ with aleatory cdfs $F_{M_{e k}}\left(\boldsymbol{m}_{e k} \mid z_{e k}, \pi_{e k}\right)$, then:

Ouput of the plural vector $=$ aleatory cdf $F_{M_{k}}\left(\boldsymbol{m}_{k} \mid \mathbf{z}_{k}\right)$

$=\sum_{e=1}^{n_{e}} p_{e} \int_{\text {all } \pi_{e k}} F_{M_{e k}}\left(\boldsymbol{m}_{e k} \mid z_{e k}, \pi_{e k}\right) \mathrm{d} F_{\Pi_{e k}}\left(\pi_{e k} \mid \pi_{\Pi_{e k}}\right)$

where $\mathbf{z}_{k}=\left(z_{1 k}, z_{2 k}, \ldots, z_{n_{e} k}\right)$ is the matrix expressing known information (set of $n_{e}$ individual input vectors). Methods for building plural models as well as eliciting the experts' probabilities $p_{e}$ are discussed in [43, 44].

The above expressions of the output of plural model are based on the so-called Apostolakis-Laskey scheme [43] which can be used for the model uncertainty analysis in CBA setting [39]. Viewed in the context of the accident simulation described in Sec 3.2, these expressions are impractical because they take the measures $p_{e}$ and $F_{\Pi_{e k}}\left(\pi_{e k} \mid \pi_{\Pi_{e k}}\right)$ out of the uncertainty propagation which yields the action model $H_{X}(\boldsymbol{x})$. In order to incorporate $p_{e}$ and $F_{\Pi_{e k}}\left(\pi_{e k} \mid \pi_{\Pi_{e k}}\right)$ in this propagation, the model set $\boldsymbol{m}_{e k}\left(\boldsymbol{z}_{e k} \mid \boldsymbol{\pi}_{e k}\right)\left(e=1,2, \ldots, n_{e}\right)$ should be integrated into the accident simulation by taking the following three steps: (1) a value $e_{j}$ of a discrete rv $E$ with the probability mass function $P(E=e)=p_{e}(e=1,2$, $\left.\ldots, n_{e}\right)$ is generated in the $j$ th inner loop and $l$ th outer loop repetition; (2) the $e_{j}$ th model $\boldsymbol{m}_{e_{j} k}\left(\pi_{e_{j} k} \mid \pi_{e_{j} k}\right)$ is chosen to describe the physical phenomenon represented by $E_{k}$; (3) the model output $\boldsymbol{m}_{e_{j} k}\left(\boldsymbol{z}_{e_{j} k j} \mid \pi_{e_{j} k l}\right)$ is computed and used to decide whether $E_{k}$ occurs or does not occur and, if occurs, to provide input values for the subsequent models $\boldsymbol{m}_{k+1}\left(z_{k+1} \mid \pi_{k+1}\right), \ldots, \boldsymbol{m}_{n_{k}}\left(z_{n_{k}} \mid \pi_{n_{k}}\right)$.

A practical application of the procedure proposed in Sec 3.2 can be complicated by the fact that mathematical models, which embody the state-of-knowledge about the physical phenomena related to the events $E_{k}$ $\left(k=1,2, \ldots, n_{k}-1\right)$ and of which the models $\boldsymbol{m}_{k}\left(z_{k} \mid \pi_{k}\right)$ can be composed, are typically deterministic and imperfect (not error-free). This can require to supplement deterministic constituents $m_{1 k}\left(z_{k} \mid \pi_{k}\right), m_{2 k}\left(z_{k} \mid \pi_{k}\right)$, ... of the models $\boldsymbol{m}_{k}\left(z_{k} \mid \pi_{k}\right)$ with subjective uncertainty distributions which could allow to apply these models in the Bayesian framework. Candidate approaches to such 
Table 6. Survey of literature on assigning and updating the epistemic uncertainty distributions used in the case study (Sec 4.2)

\begin{tabular}{l}
\hline \hline Unobservable parameter(s): components of $\pi_{P_{0}} \quad$ Parent $\operatorname{model}(\mathbf{s}): H_{0}\left(z_{0} \mid \pi_{0}, p_{0}\right)$ \\
\hline Measure(s) of epistemic uncertainty: $F_{P_{0}}\left(p_{0} \mid \pi_{P_{0}}\right)$ \\
Form of evidence: $E=\{r$ collisions in the time interval $[0, t]\}$ \\
Updating procedure: for the alpha parameter, $\pi_{1 P_{0}}^{\prime}=\pi_{1 P_{0}}+r ;$ for the beta parameter, $\pi_{2 P_{0}}^{\prime}=\pi_{2 P_{0}}+t$ \\
Prior constructing procedure: constructing the prior distribution for $\pi_{P_{0}}$ is considered, eg [31] \\
\hline Unobservable parameter(s): components of $\pi_{60} \quad$ Parent model(s): cdf $F_{Z_{60}}\left(z_{60} \mid \pi_{60}\right)$ \\
\hline Measure(s) of epistemic uncertainty: $F_{\Pi_{60}}\left(\pi_{60} \mid \pi_{\Pi_{60}}\right)$ \\
Form of evidence: $E=\left\{z_{60, i}, i=1,2, \ldots\right\}$, where $z_{60, i}=$ value of $Z_{60}$ obtained from the $i$ th experiment (collision) \\
Updating procedure: posterior distributions in closed form are not available; the Bayes formula for density updating \\
must be evaluated numerically \\
Prior constructing procedure: constraints on the distribution moments, $0<\pi_{1,60}<1$ and $0<\pi_{2,60}<0,25$, allow to apply \\
the maximum-entropy method to assigning the prior density $f_{\Pi_{60}}\left(\pi_{60}\right)[31]$
\end{tabular}

\begin{tabular}{cc}
\hline \hline Unobservable parameter(s): components of $\pi_{2}$ & Parent model(s): fragility function $F_{22}\left(z_{2} \mid \pi_{2}\right)$ \\
\hline Measure(s) of epistemic uncertainty: $F_{\Pi_{2}}\left(\pi_{2} \mid \pi_{\Pi_{2}}\right)$ &
\end{tabular}

Form of evidence: $E=\left\{\left(z_{2 i}, \quad P_{e}\left(E_{2} \mid z_{2 i}\right)\right), i=1,2, \ldots\right\}$, where $z_{2 i}=$ value of the collision energy $z_{2} ; P_{e}\left(E_{2} \mid z_{2 i}\right)=$ estimate of the probability of explosion $E_{2}$ given a collision with the energy $z_{2 i}$

Updating procedure: assigning and updating cdf $F_{\Pi_{2}}\left(\pi_{2} \mid \pi_{\Pi_{2}}\right)$ can be stated as a problem of a simple linear regression analysis in the Bayesian setting if the pairs $\left(z_{2 i}, P_{e}\left(E_{2} \mid z_{2 i}\right)\right), i=1,2, \ldots$ are represented in the coordinate system of a normal probability graph paper; the components of $\pi_{2}$ can be expressed as functions of uncertain linear regression parameters and the prior $F_{\Pi_{2}}\left(\pi_{2} \mid \pi_{\Pi_{2}}\right)$ improved by updating these regression parameters, eg, [40] for updating priors of regression parameters

Prior constructing procedure: see [41] for assigning priors to parameters of linear regression models; see also [42] for estimating fragility functions from expert opinions

Unobservable parameter(s) $\pi_{11}, \pi_{21}, \pi_{13}, \pi_{23}, \pi_{33}, \pi_{43} \quad$ Parent $\operatorname{model}(\mathbf{s}): \boldsymbol{m}_{1}\left(\boldsymbol{z}_{1} \mid \pi_{1}\right)$ and $\boldsymbol{m}_{3}\left(\mathrm{Z}_{3} \mid \pi_{3}\right)$

Measure(s) of epistemic uncertainty: $F_{\Pi_{i 1}}\left(\pi_{i 1} \mid \pi_{\Pi_{i 1}}\right)(i=1,2), F_{\Pi_{i 3}}\left(\pi_{i 3} \mid \pi_{\Pi_{i 3}}\right)(i=1,2,3,4)$

Form of evidence: $\quad E^{\prime}=\left\{\pi_{i}^{\prime}, i=1,2, \ldots\right\}, \quad E^{\prime \prime}=\left\{\ln \pi_{i}^{\prime \prime}, i=1,2, \ldots\right\}, \quad E^{\prime \prime \prime}=\left\{\ln \pi_{i}^{\prime \prime \prime}, i=1,2, \ldots\right\}, \quad$ where $\quad \pi_{i}^{\prime}=$ experimental value of the tolerable energy of collision; $\pi_{i}^{\prime \prime}$ and $\pi_{i}^{\prime \prime \prime}=$ experimental values of relative overpressure and relative impulse

Updating procedure: procedures developed for updating priors of mean and variance (precision) of a normal pd allow expressing posterior distributions in closed form, eg, [40]

Prior constructing procedure: see prior constructing procedures given by Congdon [40]

Unobservable parameter(s): $\pi_{53}, \pi_{63}, \pi_{73}, \pi_{83} \quad$ Parent $\operatorname{model}(\mathbf{s}): \boldsymbol{m}_{3}\left(z_{3} \mid \pi_{3}\right)$

Measure(s) of epistemic uncertainty: $F_{\Pi_{i 3}}\left(\pi_{i 3} \mid \pi_{\Pi_{i 3}}\right)(i=5,6,7,8)$

Form of evidence: $E^{\prime}=\left\{\left(p_{i}^{+}, z_{13, i}, z_{23, i}\right), i=1,2, \ldots\right\}, E^{\prime \prime}=\left\{\left(l_{i}^{+}, z_{13, i}, z_{23, i}\right), i=1,2, \ldots\right\}$, where $p_{i}^{+}$and $l_{i}^{+}=$values of the positive overpressure and positive impulse measured in the ith experiment, respectively; $z_{13, i}$ and $z_{23, i}=$ mass and standoff of explosive charge used in the $i$ th experiment, respectively

Updating procedure: $\pi_{53}, \pi_{63}, \pi_{73}$, and $\pi_{83}$ are parameters of the non-linear, multiple regression models $m_{13}^{\prime}\left(z_{3} \mid \cdot\right)$ and $m_{23}^{\prime}\left(z_{3} \mid \cdot\right)$; to the best of our knowledge posterior distributions of these parameters cannot be expressed in closed form and, moreover, practical procedures of numerical updating priors of $\pi_{53}, \pi_{63}, \pi_{73}$, and $\pi_{83}$ specifically and parameters of non-linear regression models generally are still to be developed

Prior constructing procedure: the $\operatorname{cdfs} F_{\Pi_{i 3}}\left(\pi_{i 3} \mid \pi_{\Pi_{i 3}}\right)(i=5,6,7,8)$ were chosen by assigning normal distributions to respective regression parameters; mean values of these distributions were chosen to be equal to values of conventional least squares estimates of $\pi_{53}, \pi_{63}, \pi_{73}$, and $\pi_{83}$ given by Luzin et al [25] 
a probabilistic "upgrading" of the deterministic models are approach of adjustment factors [44] and approach known as a Bayesian processor of forecast [45]. Both approaches consist in modifying output variables of a deterministic model by coupling them with random adjustment factors (statistical post-processors) which are described by prior (posterior) distributions. The adjustment factors are applicable in CBA setting and the uncertainty expressed by these factors can be of the epistemic type only or both epistemic and aleatory [39, 44]. An example of applying the adjustment factors are the variables $\pi^{\prime \prime}$ and $\pi^{\prime \prime \prime}$ included in the blast wave model $\boldsymbol{m}_{3}\left(z_{3} \mid \pi_{3}\right)$ (see Sec 4.2.3).

\section{Discussion: how to apply Bayesian action models to damage assessment?}

When selected the action model $H_{X}(\boldsymbol{x})$ defined by Eq (1) may rise questions concerning its (i) complexity, (ii) ability to be updated in the Bayesian framework when additional knowledge (information on the AA in question and/or the events $E_{k}$ escalating into $O A A$ ) becomes available as well as (iii) suitability for assessing damage to objects of structural and mechanical engineering exposed to AAs. Answers to these questions can be formulated as three arguments in favour of the model $H_{X}(\boldsymbol{x})$.

Firstly, the complexity of the model $H_{X}(\boldsymbol{x})$ is determined by its informativeness. It quantifies two types of uncertainty, aleatory and epistemic, and provides, so to say, a full informative service for the analyst. The model $H_{X}(\boldsymbol{x})$ enables one to quantify the epistemic uncertainty (state-of-knowledge) related to the frequency $p_{a}$ of $O A A$ and exceedance probability $1-P(X \leq x \mid O A A)$ associated with given $\boldsymbol{x}$, where " $\boldsymbol{X} \leq \boldsymbol{x}$ " means "is less componentwise". In principle, the epistemic uncertainty expressed by cdf $F_{P_{a}}\left(p_{a} \mid \pi_{a}\right)$ and probabilistic weights $p_{i}$ can be averaged out and so a simpler version of $H_{X}(\boldsymbol{x})$ obtained; however, the selection of $H_{X}(\boldsymbol{x})$ is not an end in itself and it makes sense to propagate the epistemic uncertainty further by introducing epistemic uncertainty measures into results of assessing damage from AAs.

Secondly, the model $H_{X}(\boldsymbol{x})$ can be updated in the Bayesian framework; however, this can be done not directly but by reapplying the procedure used to its selection. This procedure implies that additional knowledge should be used for standard Bayesian updating some of the "lower-level" epistemic cdfs $F_{P_{0}}\left(p_{0} \mid \pi_{P_{0}}\right)$, $F_{\Pi_{0}}\left(\pi_{0} \mid \pi_{\Pi_{0}}\right)$, and $F_{\Pi_{k}}\left(\pi_{k} \mid \pi_{\Pi_{k}}\right)$. Once the "lowerlevel" distributions have been updated, $H_{X}(\boldsymbol{x})$ can be updated by reapplying the model selection procedure using these distributions. Generally additional knowledge should decrease the epistemic uncertainty quantified by $H_{X}(\boldsymbol{x})$.

Thirdly, an apparently "loose" structure of the model $H_{X}(\boldsymbol{x})$ allows a simple integration of its constituents into damage assessment, provided that results of this as- sessment are expressed in terms of probabilities (frequencies) of damage events. If a particular damage to a structural or mechanical object, say, industrial building or distillation column is interpreted as a random event $D_{d}$, one can apply aleatory cdfs $F_{X_{i}}\left(\boldsymbol{x} \mid \pi_{\boldsymbol{x}_{i}}\right)$ to calculating a set of damage probabilities, $P_{i}\left(D_{d} \mid O A A\right) \quad(i=1,2$, $\ldots, n)$, each defined as

$$
P_{i}\left(D_{d} \mid O A A\right)=\int_{\text {all } \boldsymbol{x}} P\left(D_{d} \mid \boldsymbol{x}\right) \mathrm{d} F_{\boldsymbol{X}_{i}}\left(\boldsymbol{x} \mid \pi_{\boldsymbol{x}_{i}}\right),
$$

where $P\left(D_{d} \mid \boldsymbol{x}\right)$ is the so-called fragility function, the value of which is equal to a conditional probability of $D_{d}$ given that an AA with characteristics $\boldsymbol{x}$ has been imposed (eg, [16]). The epistemic probabilistic weights $p_{i}$, which are assigned in the model $H_{X}(\boldsymbol{x})$ to cdfs $F_{X_{i}}\left(\boldsymbol{x} \mid \pi_{\boldsymbol{x}_{i}}\right)$, can be automatically assigned to the damage probabilities $P_{i}\left(D_{d} \mid O A A\right)$. The variability of the set $P_{i}\left(D_{d} \mid O A A\right)(i=1,2, \ldots, n)$ can be used to assess how certain is a statement about the likelihood of the damage represented by $D_{d}$.

The expression of $P_{i}\left(D_{d} \mid O A A\right)$ transforms the model $H_{X}(\boldsymbol{x})$ into a set of intermediate uncertainty measures, $\left\{F_{P_{a}}\left(p_{a} \mid \pi_{a}\right),\left(P_{i}\left(D_{d} \mid O A A\right), p_{i}\right) \quad(i=1,2, \ldots\right.$, $n)\}$, which can be used in different ways to extracting a message of damage assessment for decision-makers. For instance, one can calculate a single probability $P\left(D_{d} \mid O A A\right)$ and frequency $H\left(D_{d}\right)$ of the damage event $D_{d}$, which are obtained by simple averaging out measures of epistemic uncertainty and can be called in line with Bayesian terminology the "predictive" ones, namely,

$$
P\left(D_{d} \mid O A A\right)=\sum_{i=1}^{n} P_{i}\left(D_{d} \mid O A A\right) p_{i}
$$

and

$$
H\left(D_{d}\right)=P\left(D_{d} \mid O A A\right) \int_{\text {all } p_{\mathrm{a}}} p_{a} \mathrm{~d} F_{P_{a}}\left(p_{a} \mid \pi_{a}\right) .
$$

Frequencies like $H\left(D_{d}\right)$ can be calculated for a set of damage events, $D_{d}\left(d=1,2, \ldots, n_{d}\right)$, which includes either all foreseeable damage events, together with the event of no-damage (survival), or only some damage events of interest. With the frequencies $H\left(D_{d}\right)$, a comprehensive result of damage assessment can be represented by a risk of damage $[14,15]$. It can be expressed as the set $\left\{\left(H\left(D_{d}\right), O_{d}\right),\left(d=1,2, \ldots, n_{d}\right)\right\}$, where $O_{d}$ is the outcome of $D_{d}$, the significance of which can be measured, say, in lost money. The set of pairs "damage frequency" and "outcome of the damage" is a somewhat simplified version of the general definition of risk used in the field of QRA (eg, [11]). The above risk of damage is not the only form of message which can be obtained using CBA as an approach underlying the selection of $H_{X}(\boldsymbol{x})$. Aven and Pörn [18] as well as Apeland et al [20] provide a broad methodological discussion about representation and attractiveness of results of QRAs carried out by applying CBA. 


\section{Conclusions}

The prime objective of the present paper was to propose a computational procedure intended for a selection of mathematical models for actions induced during man-made accidents or, in brief, accidental actions (AAs). The selection of mathematical models for AAs (action models) can be carried out in the framework of the quantitative risk assessment (QRA). Methods of QRA allow taking into account the specific nature of the physical phenomena occurring as AAs. A proper context for selecting action models is provided by the classical Bayesian approach to QRA. This approach is well suited to quantifying aleatory (stochastic) and epistemic (state-ofknowledge) uncertainties related to AAs.

The proposed procedure is based on a stochastic simulation of accident sequences (courses) which lead to an imposition of AA. The essence of the procedure consists in relating the aleatory and epistemic uncertainties in characteristics of AA to the uncertainties in physical phenomena, the sequences of which end in an imposition of the AA. Thus the procedure serves the purpose of propagating uncertainties. Action models selected by applying the proposed procedure are probabilistic and contain measures of both aleatory and epistemic uncertainty.

A practical application of the proposed procedure requires establishing a set of mathematical models describing the physical phenomena which precede an occurrence of AA. These models determine initial information (hard data and expert judgements) which must be collected and transformed via uncertainty propagation into an action model. The Bayesian approach to QRA provides a formal basis for combining hard data and expert judgements within the problem of predicting AAs. Compensation of scarce experience data by subjective information (expert opinions, judgements of analysts and analyst groups, etc.) is a burning issue in case of AAs.

A short review of application of expert judgements to the prediction of AAs is given in this paper. From this review it can be concluded that the number of recipes given in QRA and Bayesian statistical theory for a formal use of subjective information is relatively large. However, a systemisation is necessary to allow applying these recipes on the practical level, that is, the level of predicting AAs and damage from them.

The simulation-based procedure proposed in the paper can be used for reliability-based design of protective structures as well as damage assessment and risk studies within the methodological framework provided by the classical Bayesian approach.

\section{References}

1. Baker, W. E.; Cox, P. A.; Westine, P. S. et al. Explosion hazards and evaluation. Amsterdam etc.: Elsevier, 1983. $473 \mathrm{p}$.
2. Marshall, V. C. Major chemical hazards. Chichester: Ellis Horwood Ltd., 1987. 512 p.

3. ISO 2394: 1998 (E). General principles on reliability for structures. Geneve: ISO, 1998.

4. DNV-OS-A101. Offshore standard. Safety principles and arrangements. Høvik: Det Norske Veritas, 2001. 173 p.

5. Watson, A. J.; Hobbs, B.; Wright, S. J. Experimental modelling of explosive blast effects on structural steel cladding. In: Bulson, P. S. (ed). Structures under Shock and Impact II. London: Thomas Telford, 1992, p. 571-586.

6. Cánovas, M. F. et al. Impact effects on the primary fragmentation generated by the HE81 mortar grenade on conventional concrete and steel fibres reinforced concrete. In: Bulson, P. S. (ed). Structures under Shock and Impact III. Southampton, Boston: Computational Mechanics Publications, 1994, p. 37-44.

7. Slater, J. E.; Ritzel, D. V.; Thibault, P. A. Development of computational methods and conduct of experimental tests for blast loading analysis. In: Bulson, P. S. (ed). Structures under Shock and Impact III. Southampton, Boston: Computational Mechanics Publications, 1994, p. 382-392.

8. Cooke, R. M. Uncertainty modelling: examples and issues. Safety Science, 26, 1997, p. 49-60.

9. Hauptmanns, U. A procedure for analysing the flight of missiles from explosions of cylindrical vessels. Journal of Loss Prevention in Process Industry, 14, 2001, p. 395402.

10. Apostolakis, G. The concept of probability in safety assessments of technological systems. Science, 4987(250), 1990, p. 1359-1364.

11. Kumamoto, H.; Henley, E. J. Probabilistic risk assessment for engineers and scientists, 2nd ed, New York: IEEE Press, 1996. $511 \mathrm{p}$.

12. Vrouwenvelder, T. Stochastic modelling of extreme action events in structural engineering. Probabilistic Engineering Mechanics, 5, 2000, p. 109-117.

13. Vaidogas, E. R. Probabilistic framework for assessing risks to structures stemming from accidental explosions. Journal of Civil Engineering and Management, Vol 8, No 2, 2002, p. 108-116.

14. Vaidogas, E. R. Accidental explosions: Bayesian uncertainty handling in assessing damage to structures. In: Der Kiureghian, A.; Manadat, S.; Pestana, J. M. (eds). Proceedings of ICASP9, Vol 1. Rotterdam: Milpress, 2003, p. 191-199.

15. Vaidogas, E. R. Predictive, epistemic approach to assessing damage to structures arising from man-made accidents. International Journal of Materials \& Structural Reliability, 2, 2004, p. 13-33.

16. Sundararajan, C.; Vo, T. V. Probabilistic structural mechanics in system and plant risk assessment. In: Sundararajan, C. (ed). Probabilistic Structural Mechanics Handbook. New York: Van Nostrand, Reinhold, 1993, p. 188-210.

17. Ravindra, M. K. Seismic risk assessment. In: Sundararajan, C. (ed). Probabilistic Structural Mechanics Handbook. New York: Van Nostrand, Reinhold, 1993, p. 429-464.

18. Aven, T.; Pörn, K. Expressing and interpreting the results of quantitative risk analyses. Review and discussion. Reliability Engineering \& System Safety, 61, 1998, p. 3-10. 
19. Li, C. Q. A stochastic model of severe thunderstorms for transmission line design. Probabilistic Engineering Mechanics, 15, 2000, p. 359-364.

20. Apeland, S.; Aven, T.; Nilsen, T. Quantifying uncertainty under predictive, epistemic approach to risk analysis. Reliability Engineering \& System Safety, 75, 2002, p. 93-102.

21. Winkler, R. B. Uncertainty in probabilistic risk assessment. Reliability Engineering \& System Safety, 54, 1996, p. 127132.

22. Hofer, E.; Kloss, M. et al. An approximate epistemic uncertainty analysis approach in the presence of epistemic and aleatory uncertainties. Reliability Engineering \& System Safety, 77, 2002, p. 229-238.

23. Vaidogas, E. R. Uncertainties related to hazard functions of accidental explosions. In: Report of the International Conference "Safety, Risk and Reliability - Trends in Engineering". Zürich: IABSE, 2001, p. 495-500.

24. Ivanof, K.; Lialin, V. A. Passive safety of car. Moscow: Transport, 1979. 233 p. (in Russian).

25. Rubinstein, R. Y.; Melamed, B. Modern simulation and modelling. New York: Wiley, 1998. 411 p.

26. Luzin, O. V. et al. Analysis of blast-loaded structures. In: Korenev, B. (ed). Dynamics of Structures Exposed to Special Effects. Moscow: Strojizdat, 1982, p. 5-28 (in Russian).

27. Tedesco, J. W.; McDougal, W. G.; Ross, C. A. Structural dynamics. Theory and applications. Menlo Park, California: Addison Wesley, Longman, Inc., 1999. 714 p.

28. Kaplan, S.; Burmaster, D. How, when, why to use all the evidence. Risk Analysis, 19, 1999, p. 55-62.

29. Clement, R. T.; Winkler, R. L. Combining probability distributions from experts in risk analysis. Risk Analysis, 19, 1999, p. 187-202.

30. Smith, A. F. M. An overview of the Bayesian approach. In: Sander, P.; Badaux, R. (eds). Bayesian Methods in Reliability. Dordrecht etc.: Kluwer, 1991, p. 15-79.

31. Siu, N. O.; Kelly, D. Bayesian parameter estimation in probabilistic risk assessment. Reliability Engineering \& System Safety, 62, 1998, p. 89-116.

32. West, M. Modelling expert opinion. In: Bernardo, J. M., DeGroot, M. H.; Lindley, D. V.; Smith, A. F. M. (eds). Bayesian statistics 3. Oxford: Oxford University Press, 1988, p. 493-508.
33. West, M. Modelling agent forecast distributions. Journal of Royal Statistical Society, B 54, 1992, 553-567.

34. West, M., Crosse, J. O. Modelling probabilistic agent opinion. Journal of Royal Statistical Society, B 54, 1992, p. 285-299.

35. Mosleh, A.; Bier, V. M.; Apostolakis, G. A critique of current practice for the use of expert judgement in probabilistic risk assessment. Reliability Engineering \& System Safety, 20, 1988, p. 63-85.

36. French, S.; Cooke, R. M.; Wiper, M. P. The use of expert judgement in risk assessment. In: Sander, P.; Badaux, R., editors. Bayesian methods in reliability. Dordrecht et al: Kluwer, 1991, p. 119-134.

37. Aven, T. On the Bayesian approach to risk analysis. In: Guedes Soares, C., (ed). Proceeding of ESREL'97. Oxford: Elsevier/Pergamon, 1997, p. 1647-1652.

38. USNRC. An approach for using probabilistic risk assessment in risk decisions on plant-specific changes to licensing basis. Regulatory Guide 1.174. USNRC Draft DG-1061, 1997.

39. Nilsen, T.; Aven, T. Models and model uncertainty in the context of risk analysis. Reliability Engineering \& System Safety, 79, 2003, p. 309-317.

40. Congdon, P. Bayesian statistical modelling. Wiley, Chischester, etc, 2001, $354 \mathrm{p}$.

41. Mosleh, A.; Apostolakis, G. The assessment of probability distributions from expert opinions with an application to seismic fragility curves. Risk Analysis, 6, 1986, p. 447461.

42. Watson, S. R. The meaning of probability in probabilistic safety analysis. Reliability Engineering \& System Safety, 45, 1994, p. 261-269.

43. Devooght, J. Model uncertainty and model inaccuracy. Reliability Engineering \& System Safety, 59, 1998, p. 171185.

44. Zio, E.; Apostolakis, G. E. Two methods for the structured assessment of model uncertainty by experts in performance assessment of radioactive waste repositories. Reliability Engineering \& System Safety, 54, 1996, p. 225-241.

45. Krzysztofowicz, R. Bayesian forecasting via deterministic model. Risk Analysis, 19, 1999, p. 739-749.

\section{APKROVOS, VEIKIANČIOS KONSTRUKCIJAS TECHNOGENINIŲ AVARIJŲ METU: PROGNOZAVIMAS NEAPIBRĖŽTUMUS MODELIUOJANT STOCHASTINIO MODELIAVIMO BŪDU}

\section{E. R. Vaidogas}

\section{Santrauka}

Mechaniniai, terminiai ir cheminiai poveikiai, pasireiškiantys sunkių technogeninių avarijų metu (avariniai poveikiai), gali sukelti didelius statybinių konstrukcijų pažeidimus ir griūtis. Prognozuoti šiuos poveikius yra svarbu norint tų pažeidimų ir griūčių ir išvengti. Logiškas tokio prognozavimo rezultatas yra tikimybiniai matematiniai modeliai, nusakantys avarinių poveikių pasireiškimo tikètinumą ir charakteristikas. Daugeliu atvejų tokius modelius reikia parinkti stokojant informacijos apie poveikius, sukeliančius fizinius reiškinius. Siūloma stochastinio modeliavimo procedūra, kuri turètų palengvinti avarinio poveikio matematinio modelio parinkimą ribotos informacijos sąlygomis. Ši procedūra sukurta laikantis klasikinio Bẻjeso požiūrio i̇ rizikos analizę principų. Pagrindinè straipsnio idèja yra ta, kad statistinès imtys, būtinos 
poveikių modeliams parinkti, gali būti generuotos atliekant stochastinị avarijos modeliavimą. Siūloma stochastinio modeliavimo procedūra gali būti taikoma vertinant potencialius konstrukcijų pažeidimus avariniais poveikiais ir atliekant rizikos analizę, grindžiamą klasikinio Bèjeso požiūrio principais.

Raktažodžiai: technogeninė avarija, avarinė apkrova, rizikos vertinimas, neapibrèžtumas, Bèjeso požiūris, stochastinis modeliavimas.

Egidijus Rytas VAIDOGAS. Assoc Prof of Structural Engineering at the Dept of Reinforced Concrete Structures of VGTU. Assoc Prof, 2000, Doctor (structural engineering), 1994. Member of IABSE since 2000. His actual research interests include assessment of reliability of structures and application of methods of quantitative risk assessment to the design of structures. 